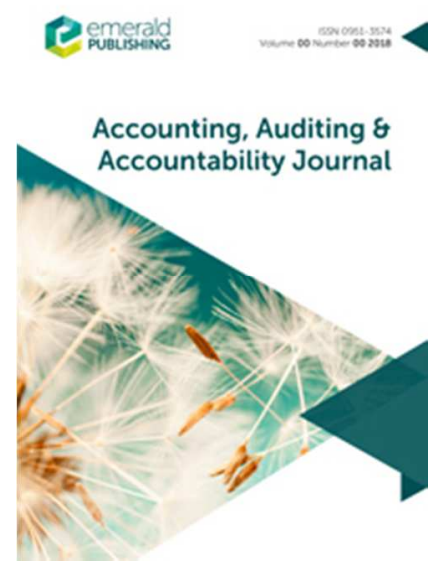

SOCIAL INEQUITY, TAXES AND WELFARE IN AUSTRALASIA

\begin{tabular}{|r|l|}
\hline Journal: & Accounting, Auditing \& Accountability Journal \\
\hline Manuscript ID & AAAJ-02-2016-2432.R4 \\
\hline Manuscript Type: & Research Paper \\
\hline Keywords: & Tax evasion, Welfare fraud, Social dominance, Prejudice, Inequity \\
\hline \multicolumn{2}{|}{} \\
\hline
\end{tabular}




\section{SOCIAL INEQUITY, TAXES AND WELFARE IN AUSTRALASIA ${ }^{1}$}

Purpose: The major aims of this study are to highlight, challenge and explain the inequitable treatment of tax and welfare fraudsters in the criminal justice systems of Australia and New Zealand. A second objective of the study is to highlight the importance of critical tax research as an instrument to agitate for social change.

Design / Methodology / Approach: A survey captures 3,000 respondents' perceptions of the likelihood that different 'types' of people will commit welfare or tax fraud. Using social dominance theory, we investigate the extent to which prejudice impacts on attitudes towards those engaged in these fraudulent activities.

Findings: We find the presence of traditional stereotypes, such as the perception that businessmen are more likely to commit tax fraud and people receiving welfare assistance are more likely to commit fraud. We also find strong preferences towards respondents' own ingroup.

Value: The study highlights the difficulty of social change in the presence of strong in-group preference and prejudice. Cognisance of in-group preference is relevant to the accounting profession where elements of self-regulation remain. In-group preferences may impact on services provided, as well as professional development and education.

Social Implications: Where in-group preference exists among those who construct and enforce the rules relating to investigations, prosecutions and sentencing of tax and welfare fraud, it is perhaps unsurprising that welfare recipients attract less societal support than other groups who have support from their own in-groups that have greater power, resources and influence.

Keywords: tax evasion; welfare fraud; prejudice; social dominance; inequity

\section{INTRODUCTION}

Like accounting, tax is not just about reporting and monitoring; it is more than a set of rules to determine who should pay what in certain circumstances. Instead, it is a social construction compiled by the state, in conjunction with professional bodies and interested entities. As noted in Chua's seminal article (1986:601), accounting is a common set of philosophical assumptions about knowledge, the empirical world, and the relationship between theory and practice'. The same observation may be made of taxation. The taxation discipline has its own rules and generally understood ways of doing things. Moreover, it has its own generally accepted processes for addressing transgressions from these rules and

\footnotetext{
${ }^{1}$ The authors are grateful for the constructive feedback and guidance provided by two anonymous reviewers and the editors in the publication of this article.
} 
regulations. Other social institutions, such as welfare agencies, have similarly understood and taken for granted rules pertaining to behaviours and sanctions for wrongdoings.

This study uses the field of taxation to highlight and challenge issues of inequity and social justice. It does this by illustrating how the conceptually similar crimes of tax evasion and welfare fraud result in different outcomes in the justice system. Table 1 outlines the similarities and differences in the two crimes.

\section{(Insert Table 1 About Here)}

Table 1 shows a number of similarities in the two crimes: they are deliberate; they have the same victim; and they have the same outcome. Moreover, both are quantifiable in the form of the economic harm that results from the activity. While tax evasion is the usual description attached to tax non-compliance, in order that the conventional labels attached to the offences do not detract from the following analysis and discussion, both activities will be referred to as 'fraud' for the remainder of this article.

Table 1 also shows the two key differences in the crimes. Tax fraud has considerably more economic significance than welfare fraud - 50 times the magnitude in New Zealand in 2015/16 (Inland Revenue, 2016; Ministry of Social Development, 2016). However, Table 1 does not show the privilege shown to tax fraudsters as compared to welfare fraudsters. Thus, the first aim of this study is to illustrate how those with greater resources and influence in society receive preferential treatment when compared to those who are less powerful in society, using the tax and welfare systems for illustrative purposes. The aim extends to challenge this preferential treatment and explain why these differences continue to exist in a society that is increasingly accepting that unequal treatment of individuals is undesirable.

This study explores the role of prejudice as an explanation for the differences in treatment of tax and welfare fraudsters, using a social dominance theoretical framework. Prejudice is a concept social scientists use to describe and understand inter-group conflicts that occur in society (Duckitt, 1992). Social dominance theory highlights the presence of prejudice, as it suggests that individuals create social groups that promote hierarchies. The theory captures the extent to which individuals prefer societal relations to be equal or whether their preference is for their own group to dominate.

Extending Mitchell, Sikka and Willmott's (2001:528) encouragement for accounting scholars to more directly intervene in worldly affairs and 'report "inconvenient facts" to a wider public', the genesis of our study is the different treatments of welfare and tax fraudsters in New Zealand and Australia. In the study, we examine in- and out-groups and the extent to which individuals believe that their own group is more or less likely to commit either tax or welfare fraud. We do this by reporting on results from a large survey with 3,000 respondents.

We find strong evidence of the presence of social dominance along with traditional stereotyping. In doing so, we find in-group preference: individuals believe their own in-group is less likely to commit the crimes of tax or welfare fraud than other groups. This finding suggests that it may be difficult to change the extant inequitable treatment currently afforded to welfare fraudsters, as those with the most power and influence are, adopting social dominance theory, most likely to favour their own in-group. 
The study has a second objective, which is to make a case for more critical tax research. A Special Issue of critical tax research in 2010 noted that 'tax has not received the intellectual attention it deserves from accounting scholars and indeed is often marginalized by other apposite fields of enquiry such as political science, law and social policy' (Boden, Killian, Mulligan and Oats, 2010). ${ }^{2}$ This is despite the significance of tax to society. Thus, we pursue Dillard's claim that through 'an examination of contemporary social, economic and political issues, means for producing a critique are proposed that potentially could assist in a rational evaluation of ... social arrangements and motivate changes in practices and policies deemed irrational and oppressive' (1991:9).

The structure of this article is as follows. First, we establish the problem in section two by providing an outline of the literature that has investigated how those with greater or fewer resources are treated differently in society. We use white- and blue-collar crime for definitional purposes. We follow this with data to illustrate the different treatment of tax and welfare fraudsters in both the New Zealand and Australian justice systems. Section two also provides an outline of the concept of prejudice, used for explanatory purposes in this study. Section three engages with the critical tax research on inequity. Section four provides an outline of the theoretical framework used in the study: social dominance theory. Section five follows, which outlines the research questions, describes the research design and provides the characteristics of the survey respondents. Section six describes the research findings, which show that in-groups support similar in-groups. Section seven engages in a discussion of the issue whereby privileged in-groups hold sufficient power to maintain the status quo, resulting in a situation where we are unlikely to see outcomes improve for those who are least powerful in society. Section eight draws conclusions where, given the findings of the study, we highlight the importance of scholarly engagement in the field of tax.

\section{BACKGROUND}

The background section serves two purposes. It moves from the general to the specific, starting with the existing literature on the different treatment of individuals in different socioeconomic groups in the justice system. This serves to establish the generally accepted perception that individuals who are less privileged in society receive less favourable treatment than individuals who are more privileged. We then outline how this is visible in the New Zealand and Australian contexts, to set the scene for the particular issue examined in this study. The second aim of this section is to outline a selection of the literature on a key concept social scientists use to understand intergroup conflict: prejudice. We briefly address stereotyping, as an important connection with prejudice.

\footnotetext{
${ }^{2}$ We do not suggest that there is no critical tax research or that the critical tax research community is not engaging in excellent work. Recent activities such as the dedication of a Special Issue of Critical Perspectives on Accounting to taxation issues (2010, Issue 21, Volume 7) is one example. However, older valuable studies also exist, such as Boden, Childs and Wild (1995). However, the field remains less developed when compared to progress in accounting. There are also fewer tax scholars than accounting scholars, which impacts on the quantity of critical tax publications.
} 
This study focuses on the tax system, using tax and welfare fraud for comparative purposes. The study is located in Australia and New Zealand, as they are progressive democracies that are typically associated with egalitarian societies. New Zealand and Australia both have comprehensive welfare systems that provide income supplementation under a range of circumstances. Both countries provide assistance for those who are unemployed, unwell or in other constrained situations, such as being sole parents. While the tax systems in each country are different, they both comprehensively tax income from individuals and entities. The New Zealand tax system has a highly effective consumption tax, but few wealth taxes. Unlike New Zealand, the Australian tax system incorporates a comprehensive capital gains tax. Both countries have a broad system of legislated penalties for non-compliance with either the tax or the welfare systems. ${ }^{3}$

\section{Treatment in the Justice System}

Issues relating to the preferential treatment of 'white-collar criminals' when compared to 'blue-collar criminals' have been observed for over 60 years. Sutherland (1949) was among the first to challenge the more lenient treatment given to privileged offenders, suggesting that individuals committing white-collar crime were likely to have greater power, resources and influence: all of which were likely to impact on their treatment in the justice system. From this time, multiple scholars have highlighted the preferential treatment of those committing white-collar crime (Hagan, Nagel and Albonetti, 1980; Weisburd, Wheeler, Waring and Bode, 1991; Hudson, 1993; Nelken, 1997; Croall, 2001; Cook, 2006; Gustafson, 2009; Wacquant, 2009; Reiman and Leighton, 2013).

Various factors contribute to these different outcomes. One of these factors is class. For example, in Sutherland's seminal article of 1940, he suggests that 'respectable, or at least respected, business and professional' people had access to resources and power that facilitated committing financial crime, something that is not available to 'crime in the lower class, composed of persons of low socioeconomic status' (Sutherland, 1940:1). While Sutherland's comments date back to nearly 80 years ago, they remain valid in the present day. While our study does not directly address the issue of class, we observe Sutherland's (1940:8) suggestion that the different treatments of blue- and white-collar crime in the justice system could, at least in part, by explained by the following:

persons of the upper socio-economic class are more powerful politically and financially and escape arrest and conviction to a greater extent than persons who lack such power, even when guilty of crimes. Wealthy persons can employ skilled attorneys and in other ways influence the administration of justice in their own favour more effectively than can persons of the lower socio-economic class.

\footnotetext{
${ }^{3}$ In New Zealand, these penalties are in the Tax Administration Act 1994 and the Social Security Act 1964 for tax offending and welfare offending, respectively. Prosecutions may be taken under the Crimes Act 1961 for both offending categories, which has a higher maximum threshold of penalties. In Australia, the Tax Administration Act 1953 details the general interest charge made for non-payment of tax obligations. This Act also outlines offences and prosecution processes. The Tax Administration legislation in both countries also specifies taxpayers' rights in relation to objections, disputes and reviews. Like New Zealand, tax prosecutions in Australia may also be taken under the Criminal Code Act 1985, which provides for a higher maximum penalty.
} 
Sutherland's observation has relevance to this study, as it highlights the greater influence and resources that allow for outcomes that are more favourable in the justice system. We also note Brown's (2007) study on race and class in tax policy. Brown highlights the more punitive treatment of lower-income earners in relation to tax audits, where low-income taxpayers are far more likely to be audited than their high-income counterparts' (2007:790).

When one of the offending categories is welfare fraud, the differences between white- and blue-collar offending becomes particularly pronounced. Marston and Walsh report that case law in Australia indicates that 'a sentence of imprisonment is generally considered to be the starting point by the courts in social security fraud cases' (2008:292). This is despite the fact that financial offending undertaken by the wealthy is 'often much greater [in value] than that of common criminals' (Weisburd, Wheeler, Waring and Bode, 1991:7).

The 'type' of offending appears to be a more relevant factor in judging crimes than the harm generated from the crime. Indeed, the social construction of crime is visible in research indicating that individuals view tax offending as less serious than other offences involving similar financial amounts (Cullen, Link and Polanzi, 1982; Australian Institute of Criminology, 1986; McIntosh and Veal, 2001; Orviska and Hudson, 2002; Smith, Button, Johnston and Frimpong, 2011). Moreover, studies that ask respondents to rank crimes in order of seriousness generally report that tax fraud is less serious than other financial crimes (Australian Institute of Criminology, 1986; Evans and Kelley, 2001; Karlinsky, Burton and Blanthorne, 2004; Gupta, 2006). Thus, interpretation of fraudulent behaviour varies across contexts (Cooper, Dacin and Palmer, 2013).

A particular issue is the association made between receiving welfare and welfare fraud. There is evidence throughout multiple societies of prejudice against individuals receiving welfare benefits. The presence of welfare fraud amplifies this prejudice. Again, visibly different narratives exist in the discussions pertaining to the behaviours of those on welfare and the larger group of taxpayers. Illustrative examples from New Zealand, Australia and the United Kingdom show the pejorative language frequently used in association with those receiving welfare assistance: 'scroungers or cheats' (Marston and Walsh, 2008:287); 'wilfully idle, undeserving and lacking in moral fibre' (Cook, 1989:11); 'dole cheats' (Prenzler, 2010:2); or 'parasites demanding social security while making no contribution to the economy' (Bright, 1978:161). Meanwhile, tax fraud is 'elite crime or crimes of the powerful' (Croall, 2011:11).

The tax discipline is similar to the accounting profession, where for many decades it has been held as a profession that is, as described by Mitchell, Sikka and Willmott, 'beyond reproach' (2001:528). These authors continue to observe how powerful elites police knowledge by producing narratives that discredit alternative voices. The image of tax fraudsters is that they contribute to society; notwithstanding the fact that their non-payment of tax means their financial contributions are absent. ${ }^{5}$ Meanwhile, the image of welfare fraudsters is that they do not contribute and challenge the 'ideals of independence and self-sufficiency' that are

\footnotetext{
${ }^{4}$ The term 'dole cheats' is commonly used in Australia to refer to welfare fraudsters.

${ }^{5}$ See, for example, the work of Croall (2001).
} 
venerated in society (Fineman, 2006:135). Fineman (2006) also observes that we perpetuate practices that stigmatise those who are dependent, while ignoring the socio-economic circumstances of people's lives.

\section{Inequity in the Tax and Welfare Systems in New Zealand and Australia}

This sub-section establishes the more punitive treatment of welfare recipients, as compared to tax evaders, in New Zealand and Australia. A dominant assumption is that taxation rules and regulations are transparent, consistently applied and objective. However, evidence suggests that taxation rules may be internally consistent, but when compared across other similar activities, inequities are evident. For example, tax debtors receive more lenient debt repayment obligations then welfare debtors (Marriott, 2014). Tax debtors are more likely to have their repayments reduced or written off if they can establish serious hardship, while welfare debtors are likely to only have their debt written off when all efforts to collect the debt have been exhausted (e.g. the debtor has died and the estate is insolvent) (Marriott, 2014).

Marriott's (2014) study also highlights the different thresholds for serious hardship for welfare debtors and tax debtors. There is no definition for serious hardship in the Social Security Act 1964. The most likely outcome for welfare debtors who experience serious hardship is their repayments may reduce. By way of comparison, serious hardship for tax debtors is outlined in the Tax Administration Act 1994 as including significant financial difficulties that arise where the taxpayer ... would be unable to meet: minimum living expenses estimated according to normal community standards of cost and quality... '. 6 Tax debtors who establish they are experiencing serious hardship may request remission of their debts.

A further example of the different treatment of those who engage in welfare fraud and other financial crimes is visible in a recent change to the Social Security Act 1964. The changes create a situation where the partners of welfare fraudsters become liable for prosecution for the crime committed by their partner. They may also be liable for the debt generated from the offending. The threshold is when the partner 'ought to have known' of the offending, rather than actual knowledge. This change, which was effective from July 2014, results in a situation where the partners of welfare fraudsters are treated differently from the partners of other financial fraudsters.

Prior research has established different approaches to prosecutions by different government agencies. Recently released data from government agencies shows that the most active prosecution agencies by number of prosecutions were (in order): the New Zealand Police, the Department of Corrections, and the welfare agency - the Ministry of Social Development was third. In the financial year to 2015, the Ministry of Social Development completed 670 prosecutions. Differences are evident when comparing similar government agencies such as the Financial Markets Authority (two prosecutions) or Accident Compensation Corporation (four prosecutions). These two agencies are comparable as they are also involved in financial

\footnotetext{
${ }^{6}$ Tax Administration Act 1994, s 177A.
} 
fraud cases and Accident Compensation Corporation fraud typically relates to over claiming entitlements. A recent media report cites a Crown Law briefing as suggesting that there are different approaches adopted to prosecution depending on whether welfare receipt is part of the crime. ${ }^{7}$

Sentencing outcomes also generate disparities between welfare fraud and tax fraud offences. As the crimes are both financial, they lend themselves to comparison. Prior research has shown that for approximately three times the amount of average welfare offending $(\$ 229,471)$, tax fraudsters have one-third of the chance of receiving a prison sentence when compared to welfare fraudsters (18\%) (Marriott, 2013). The different proportions of investigations and prosecutions suggest a greater willingness by authorities to pursue those on welfare, where criminal activity is present.

Similar patterns are visible in Australia with the different treatments of welfare and tax fraudsters. As with New Zealand, only a small percentage of tax lodgements result in disputes, objections and reviews; relatively small proportions receive referral for prosecution; and conviction rates from prosecutions are high. Investigations of welfare recipients totalled 3.5 million reviews in 2009-10 (Lindley, Jorna and Smith, 2010:3). Prosecutions in Australia as a proportion of customers are typically around 0.05 per cent (Marriott, 2013). Like New Zealand, conviction rates from prosecutions are high at 99 per cent. However, the average saving per prosecuted offence is not high. Savings per prosecution range between A $\$ 29,000$ A $\$ 52,000$, but the average saving per adjustment after investigation is between $A \$ 165$ and A $\$ 199$ (Lindley, Jorna and Smith, 2010). This indicates that a large number of reviews and investigations occur in relation to very small amounts of incorrect claims.

While the information available in the two jurisdictions is not identical, both countries clearly show different treatments of welfare and tax fraudsters in the justice system. There are more investigations and prosecutions of welfare fraud than tax fraud in both countries and prosecutions commence at a lower level of offending for welfare fraud. The different approaches to investigations, prosecutions and sentencing of welfare crimes suggests a greater willingness to both pursue and to punish offending by those receiving welfare benefits.

The approach to investigation and prosecution of tax fraud may affect its perception. Tax crime is of significantly greater economic importance than welfare crime. However, the differences in treatment of the two crimes suggests that welfare fraud is the more serious offence and likely to generate considerable damage to the social fabric. Lehman and Okcabol observe this phenomenon when noting that crime management, including underreporting of some statistics, comprises 'part of a complicated political process by re-constructing meaning and imbued with social practices' (2005:615).

The approach adopted to the investigation and prosecution of tax fraud leads to underreporting of this offence, through the process of negotiated settlements. This situation arises as non-compliant taxpayers may negotiate outcomes with the tax authority and thereby

\footnotetext{
7 Reported in the Dominion Post, 17 February 2017. Available at: http://www.pressreader.com/newzealand/the-dominion-post/20170210/282535838114056, retrieved 4 March 2017.
} 
avoid prosecution. This option is not available to welfare fraudsters. While New Zealand and Australia are typically regarded as largely honest jurisdictions, ${ }^{8}$ there are clearly more than a handful of tax fraud cases in most years, which is the impression given by the few tax fraud cases that can be witnessed in the criminal courts. By way of contrast, the greater number of investigations and prosecutions, together with harsher sentences, provides support to the generally accepted belief that welfare fraud is a more serious crime than tax fraud.

The circular feature of these crimes is similar to that observed by Dillard in relation to accounting, whereby in the absence of an intervention, 'distortions are interpreted as objective representations of "real" phenomena' (1991:9). The common link with the tax and welfare fraud dynamic that is the focus of this article, is that the societal framing of welfare fraud as the more serious offence, minimises the opportunity for critique that would allow the dominant cycle to be broken. To paraphrase Dillard where accounting is replaced with tax, if the images of existence are not directed toward alternative ideological mirrors and the distorted, yet differently distorted, "realities" considered, then [tax] will continue to reinforce and reify the social system from which it emanated' (1991:9).

\section{Prejudice}

This study investigates prejudice as it 'can usefully be regarded as the outcome of conflicting group goals' (Brown, 1995:203). In the groups we examine in this study, the group that we expect to see as the oppressed group is the group of welfare fraudsters. Inevitably, there are insufficient resources to provide sufficient financial support to allow everyone in society to have their desired standard of living. Therefore, when people take more from the system for themselves, all the others in the group suffer. Tax fraudsters achieve the same outcome, but without application of similar negative attitudes.

Duckitt (1992) observes the range of concepts social scientists use to assist with explaining inter-group conflicts. Among these are tolerance, ethnocentrism, stereotype, racism, discrimination and prejudice. Prejudice is the focus on the current study as it has been 'accorded primacy' among these factors (Duckitt, 1992:7). However, the commonalities and overlaps between these concepts are recognised, and all of these concepts are likely to affect the results reported herein to a greater or lesser extent.

Typically, there are four generally agreed factors involved in the definition of prejudice:

1. It is an inter-group phenomenon;

2. It is negative;

3. It is undesirable; and,

4. It is an attitude (Duckitt (1992), citing Ashmore 1970:9). ${ }^{9}$

Attitudes are generally agreed to be a 'latent or underlying variable that is assumed to guide or influence behavior' (Fishbein and Ajzen, 1975). Attitudes are learned tendencies that

\footnotetext{
${ }^{8}$ For example, see Transparency International's Corruption Perception Index, where New Zealand and Australia both rank highly in terms of levels of public sector corruption.

${ }^{9}$ Refer to Duckitt (1992:10) for more detail on definitions of prejudice.
} 
inform responses to an object. Typically, these exist on a spectrum of favourable to unfavourable. Beliefs inform the attitude held by the individual in relation to the object, with stronger or weaker beliefs reflected in the extent of prejudice held towards the object. Fishbein and Ajzen (1975) suggest that intentions are a special case of beliefs, where the strength of the intention determines the probability that the person will perform a particular behaviour. For some time, social psychology research has united in accepting that attitudes do not appear to have a strong impact on behaviour (Terry, Hogg and Blackwood, 2001).

Intergroup relations have been the focus of many discussions on prejudice. The fundamental principle is that people favour their own groups over others (Pratto, Sidanius and Levin, 2006). Prejudice towards out-groups is generated with the practice that large numbers of people in any segment of society will broadly agree in their negative stereotypes of any given outgroup and will behave in a similar way towards them' (Brown, 1995:10). Intergroup conflicts can take the form of competition for resources, domination of one group above another, or disparities in size or status (Brown, 1995).

There are numerous examples that confirm the correlation between intergroup domination and the belief of the inferiority of the minority or oppressed group (Duckitt, 1992:101). One of the roles played by the minority group in ensuring the maintenance of the extant hierarchy is in taking the role of the scapegoat for activities disapproved of by the dominant group. Having a scapegoat facilitates cohesion within the dominant group, particularly when the minority group is already a group that is resented (Duckitt, 1992). This is particularly relevant for the welfare and tax fraud that is the topic of this study. Welfare fraudsters are a subset of people who are receiving welfare benefits. Society does not view either welfare recipients or fraudsters favourably. However, views of tax fraudsters are that they are clever or entrepreneurial. Welfare fraudsters meet the criteria of a minority or oppressed group, particularly as they are often not well organised, usually have few resources, and typically have little in the way of political influence, power or support. In contrast, tax fraudsters often retain power, influence and networks, notwithstanding criminal activity.

Duckitt (2001) reports that prejudice tends to be generalised over targets, that is, individuals who hold less favourable attitudes to one minority or oppressed group are also likely to hold less favourable attitudes to other minority or oppressed groups. There are multiple reasons why individuals may hold unfavourable views about welfare fraud. For example, the media reports on both welfare and tax fraud prosecutions. However, as welfare fraud is more likely to be prosecuted than tax fraud for a similar quantum of offending, it appears more frequently in the media. ${ }^{10}$ Thus, individuals may readily overestimate the presence of welfare fraud in society when compared to tax fraud. This phenomenon, referred to as illusory correlation in the social psychology literature, provides for individuals to assume high rates of welfare fraud among welfare recipients, as compared to tax fraud among taxpayers, due to overestimates of the frequency of welfare fraud. Thus, as noted by Hamilton and Gifford, different perceptions of groups may result solely from 'cognitive mechanisms involved in

\footnotetext{
${ }^{10}$ A search on one of the primary New Zealand news websites for 'tax evasion' returns 2,100 results and for 'benefit fraud' returns 7,590 results (search undertaken 26 February 2017 on website www.stuff.co.nz).
} 
processing information about stimulus events that differ in their frequencies of cooccurrence' (2000:161).

While the study of intergroup conflicts focuses on group ideals, the focus can also be on the influence of the group on individual attitudes. In many cases, stereotyped perspectives on out-groups act to reinforce attitudes. Brown describes stereotyping as 'a phenomenon at the heart of the study of prejudice' (1995:82) and 'a cognitive association of a social category with certain characteristics' (1995:90). More simply, they are described by Locke and Johnston (2001:108) as 'mental representations of social groups and their members which contain enough detail to allow us to know what group members are like without ever meeting them'. As well as including the likely traits of that group, these mental representations will also generate expectations of how the group members will behave. Stereotypes may result from cultural influences, socio-economic differences, or from cognitive bias that results in illusory correlations between minority or oppressed groups and infrequently occurring attributes (Brown, 1995).

Part of the wider problem in relation to attitudes towards those who engage in tax fraud and those who engage in welfare fraud is the reinforcement of knowledge relating to the two crimes. To the extent that harsher punishments are noticeable for welfare fraud, the act becomes conceptually a more serious crime. This phenomenon is raised by Mitchell, Sikka and Willmott, who observe the need to 'foster an awareness of how forms of power, including legal processes, constrain as well as enable the dissemination of knowledge' (2001:527).

The link between stereotypes and prejudice is that prejudice 'captures the affective nature of the response to members of different social groups' that may result from stereotypes (Locke and Johnston, 2001:108). Different people will hold dissimilar levels of prejudice towards certain groups, which affects how they evaluate that group. Those who are more prejudiced will use negative information about a group to judge that group and reinforce negative attitudes (Locke and Johnston, 2001).

Research outputs typically agree that stereotyping influences perceptions and judgements of people or events. For example, Darley and Gross (2000) report that individuals assessed children to be of higher or lower academic ability when told the child was from a high- or low-socioeconomic background, respectively. Darley and Gross (2000) suggest that this stereotype information does not create certainties about individuals, but rather allows hypotheses to be formed about the stereotyped individual, which are then 'tested' in a biased fashion, allowing their false confirmation.

Group affiliations may affect stereotypes. These group affiliations can result in people being more likely to agree with favourable stereotypes of their own groups and less likely to agree with favourable stereotypes of other groups: another example of illusory correlations. Thus, a form of positive social identity develops with one's own group(s), which, if threatened, may result in intergroup conflict. Social identity theory suggests that a desire for an in-group to maintain a positive social identity motivates attitudes towards that group (Terry, Hogg and Blackwood, 2001). Research has shown that even when the basis for a group membership is random, individuals favour their in-group, leading to the conclusion that where a group is 
self-inclusive, this is sufficient condition to generate hostility to other out-groups (Terry, Hogg and Blackwood, 2001).

\section{TAX AND INEQUITY}

In many ways, critical tax research is no different from critical accounting research. In a recent article commemorating 25 years of a critical accounting journal, Morales and Sponem, raise a number of objectives of the critical accounting approach including: it must question the power of any group to determine what is appropriate; it engages with theory to determine conditions to assist with emancipation; it proposes reforms and exposes dysfunctions; and it can 'convey the social, political and human complexities of accounting institutions' (Morales and Sponem (2017) citing Cooper (2014)). Critical tax research has these same objectives.

This section provides a brief illustration of the tax research that has considered inequity. In its most traditional use in taxation, equity is one of a small number of 'principles' typically considered desirable in tax policy. Different ways of looking at equity are used in the tax literature, e.g., horizontal and vertical, or progressive and regressive. The common feature is some component of 'equal' - notwithstanding that 'equal' is achievable by treating all the same, or all differently, depending on the circumstances.

Research on inequity often focuses on economic inequity, emphasising the differences in returns to capital and labour (for example, Piketty (2014)), and the subsequent relationship between inequity and increasing inequality. While this is important, this section highlights the additional contribution that critical tax research has made in extending the issue into the social and legislative domain. What is common in the majority of the literature is that it focuses on the tax system and the ways in which the regime of tax legislation and its interpretation can result in inequitable outcomes. This study adopts a different focus and instead it examines how tax, in general, is privileged. This may be because tax funds economic and social activity, and thus has a worthy objective. Meanwhile, welfare is an expenditure item, with recipients demonised for the lack of self-reliance that is the ideal when viewed through a neo-liberal lens. Work by Boden, Childs and Wild (1995) explores this further, highlighting the 'anti-welfare notions' that result from the concept of economic citizenship and the expectation of self-reliance. Brown provides further evidence in her observation that in America "“welfare recipients" equal lazy blacks, who would rather receive money from the government than work' (2007:794). This is notwithstanding the close connection of the tax and welfare schemes in relation to social objectives.

While the traditional concepts of equity within tax have been widely critiqued, inequity has not faced the same level of inquisition. Infanti captures this idea when he writes that tax equity is 'solely concerned with the fair treatment of individuals who either have the same or different incomes' (Infanti, 2008:1195). Infanti continues to observe that this represents a normative choice 'to consider economic differences - and only economic differences - in determining the fairness of a tax...' (2008:1195). Infanti's express aim is to raise consciousness of the taken for granted nature of fairness in tax research and extend thinking 
to 'embrace not only fairness to the privileged among us, but to the oppressed as well' (2008:1197).

Knauer (2014) adopts a similar stance, observing that tax policy adopts terms of neutral outcomes, while simultaneously disregarding characteristics of taxpayers that may lead to outcomes that are not neutral, such as gender, ethnic group or socioeconomic position. Instead, tax policy formation uses large-scale models that group taxpayers into income groups or expenditure categories. As Knauer (2014:210) writes, 'the fiction of taxpayer neutrality is a constituent feature of optimal tax theory, which seeks to maximize social welfare by identifying the optimal tax base'.

Similar views are visible in the field of critical tax research. Critical tax scholars have made strong contributions to address the issues Infanti and Knauer raise. While some of these are more traditional tax topics, such as the extent to which fairness affects tax burdens (for example, Farrar, 2011) or tax reform (Knauer, 2014), a range of interdisciplinary work addressing inequity is also evident. Examples include gender equity and tax (see, for example, Blumberg, 1971; Livingston, 2002; and Grown and Valodia, 2010); tax discrimination and ethnicity (see, for example, Moran and Whitford, 1996, and Brown, 2007); the role of tax administration and administrators (Tuck, 2010); how the tax system is used to influence the choices of women (Mumford, 2009); or inequities that result for samesex couples from the tax regime (Knauer, 1998), among others. A further topic that has attracted discussion is a more fundamental consideration of tax equity: who pays tax. See Infanti (2007) for a thorough discussion of this field or Gracia and Oats (2010) who discuss the related topic of tax avoidance and tax evasion. All of these examples address components of inequity relating to, or resulting from, taxation. Some directly address inequity by exploring the inequitable outcomes for different groups from the tax rules, while others show how the tax rules privilege the wealthy.

Infanti observes that 'the problem is not that "mainstream" and critical tax scholars are talking past each other, but that critical tax scholars attempt to frame their discussions in tax equity terms at all' (2008:1195). Infanti's argument is that tax equity focuses on the economic differences in determining tax fairness. Infanti refers to the insidious homogenization of the population' that results in tax equity performing a 'sanitizing and a screening function' (2008:1196) as it eliminates difference that takes other forms, such as gender or ethnicity.

Boden et al (2010:541) further develop this idea in observing the 'othering' of taxation, which may be the result of professional preference to maintain tax as a technical discipline to 'keep prying eyes from closely examining the hidden power plays at work'. Boden et al further note that positivism typically dominates tax research, whether this takes the form of black-letter law interpretations or the economic cost-benefit approach to tax policy (2010). Boden et al combine these two issues - the marginalisation of tax research and the traditional approaches to tax research - to suggest the outcome is 'the absence of an understanding of the operation of power in a social contract that touches the lives of all' (2010: 541).

Boden et al's claim about the dominance of positive research in the tax discipline is visible in all components of the literature: the publication outlets, the topics covered and the methods 
used. Moreover, this positive influence has been visible in early literature examining the behaviour of taxpayers when these taxpayers believed the tax system was inequitable. Falkinger (1988:388) captures the general finding of these studies: 'tax evasion is a means to adjust the corresponding terms of trade with government if they are perceived to be unfair' (1988:388). Many of these early tax studies were experimental (Spicer and Lundstedt, 1976; Spicer and Becker, 1980), theoretical (Cowell, 1985; Forest and Sheffrin, 2002) or empirical (Wallschutzsky, 1988) and typically reported that perceptions of inequity were a factor in taxpayers' decisions to evade their tax obligations. In time, critical research supplemented these economically grounded studies, which reaches across a broader construct of inequity than that visible in the field of public finance.

The tax community's ability to engage with technically complex material is well-established. However, Boden et al (2010:541) note that in the absence of a critical social science perspective 'this technical approach to tax fails to penetrate structural rules and their application'. Furthermore, it minimises the opportunity we have to highlight the power imbalances in society that are generated and maintained within the broader tax discipline. Thus, one of the aims of this study is to highlight the lack of equivalence in the treatment of welfare and tax offenders, where those in the group of tax offenders are more likely to represent those with the most power and influence in society. While the breadth and depth of critical tax research has undoubtedly expanded over recent decades, there is still much work needed to highlight the bias that, as captured by Knauer, 'is often obscured by the misplaced belief in the inherent neutrality of taxation' (2012:230).

\section{SOCIAL DOMINANCE THEORY}

The foundation of social dominance theory is the belief that all societies are systems of group-based social hierarchies (Sidanius and Pratto, 1999). Dominant groups are characterised by 'possession of a disproportionately large share of positive social value, or all those materials and symbolic things for which people strive' (Sidanius and Pratto, 1999:31), such as power, authority, or status. Those in subordinate groups possess a large share of negative social value, such as little power and authority, few possessions and low social status. A fundamental assumption of social dominance theory is that groups engage in behaviours to facilitate the endurance of extant hierarchies.

Sidanius et al (2004) propose that social institutions, as well as powerful individuals, disproportionately allocate desirable and undesirable goods in society, with the result that those who are less powerful receive greater amounts of undesirable goods, such as punishments. Social dominance theory proposes that an individual's measure of social dominance orientation drives attitudes towards out-groups. Social dominance orientation is 'the basic desire to have one's own primary in-group (however defined) be considered better than, superior to, and dominant over relevant out-groups' (Sidanius et al, 2001:153). The general orientation toward group-based social hierarchy is social dominance orientation (SDO) (Sidanius and Pratto, 1999:39). This study uses the 16-question SDO measurement scale (Sidanius and Pratto, 1999), as provided in Appendix I. 
People who are more social-dominance oriented will prefer hierarchy-enhancing policies that allow for group-based dominance, such as those in the criminal justice system that award harsher punishments to those in subordinate social groups. Conversely, those lower on social dominance orientation are more likely to: reflect preferences for 'egalitarianism and altruistic social concern' (Sibley, Robertson and Kirkwood, 2005:172); show preference for policies that are hierarchy-attenuating (Pratto et al, 1994); and are more likely to favour equality in the justice system. Thus, the SDO criteria may be divided into those measures that score high on dominance (questions 2, 4, 6, 8, 10, 12, 14 and 15) and those that score high on egalitarianism (questions 1, 3, 5, 7, 9, 11, 13 and 16).

There are multiple reasons for adopting SDO in this study. Social dominance theory is a powerful predictor of generalised prejudice (Duckitt et al, 2002; Duckitt and Sibley, 2010) and intergroup phenomena (Duckitt, 2001; Ho et al, 2012). In addition, SDO is an effective predictor of attitudes where the foundation of intergroup relations is inequality and where intergroup relations are characterised by high levels of threat to group values and security (Sibley, Robertson and Kirkwood, 2005). ${ }^{11}$ SDO is 'highly reliable' (Duckitt et al, 2002:76) and 'highly stable over time' (Sidanius and Pratto, 1999:68). Ho et al (2012:584) describe $\mathrm{SDO}$ as 'one of the most versatile and useful constructs for understanding socio-political ideologies, the psychology of prejudice, and intergroup behaviour'. Furthermore, studies have shown a negative correlation between social dominance orientation and traits such as empathy, tolerance and altruism (Pratto et al, 1994).

Of particular relevance to this study is the suggestion by Sidanius and Pratto (1999) that the criminal justice system is a social institution that systematically reproduces group-based hierarchy. These hierarchies are visible in the treatment of minority groups in the criminal justice system, as well as in the different treatments of tax and welfare fraudsters.

\section{RESEARCH QUESTIONS, METHODOLOGY AND CHARACTERISTICS OF RESPONDENTS}

The major aim of this study is to highlight, challenge and explain the inequity resulting from the treatments of different societal groups. This section commences with the research questions and research design adopted to address these aims. The section also outlines the characteristics of the survey respondents.

\section{Research Questions}

The study focuses on prejudiced attitudes towards different types of people. As noted in the literature in section three, one of the aims of critical accounting (and tax) research is to question and challenge power relations and situations that result from power relations. Given the anti-welfare notions highlighted in section three, we expect attitudes towards those who are engaging in welfare fraud to be more punitive than towards those who engage in tax

\footnotetext{
${ }^{11}$ For example, Sibley, Robertson and Kirkwood (2005) have used SDO to predict attitudes towards MāoriPakeha relations in New Zealand.
} 
fraud. This expectation results from the perception of a generally negative attitude towards those who are in receipt of welfare, notwithstanding any welfare fraud. Therefore, we expect exacerbation of this attitude when fraudulent activity is present. This leads to the first research question in our study.

1. To what extent are attitudes towards welfare fraud more negative than attitudes towards tax fraud?

By asking this question in the New Zealand and Australian environments, which are often believed to be relatively tolerant societies, we provide further support for the extant literature that illustrates the presence of prejudice against those who are marginalised in society. We subsequently set out to examine the influence of prejudice on attitudes and for this we use social dominance theory. Following social dominance theory, we expect that individuals will identify more positively with their own group. Thus, our second research question is:

2. To what extent do individuals believe that their own group is more or less likely to commit tax fraud or welfare fraud?

This potential presence of inter-group stereotypes and prejudice against out-groups resulted in the use of social dominance theory for analytical purposes in this study. The theory allows us to highlight where equal relations are preferred, or whether an individual prefers their own group to dominate. In asking this question through the frame of social dominance, we examine whether prejudice within hierarchies exists that will limit potential social change.

\section{Research Design}

We collect data via an online survey. A representative sample of the New Zealand and Australian population received the electronically distributed survey. An independent research company holding a database comprised of individuals belonging to a retail rewards programme in each country distributed the email. The database held approximately half of the population in both New Zealand and Australia. While the database holds a large proportion of the population, as it is a retail rewards scheme, higher socio-economic individuals have greater representation. However, this limitation does not restrict the targeting of a representative sample of the New Zealand and Australian populations based on the most recent census data.

We excluded those aged under the age of 18 due to their limited engagement with the welfare or tax systems. Individuals received rewards in the form of retail 'points' from the retail reward scheme for participating in the survey. ${ }^{12}$ This ensured anonymity of respondents from the researchers. The study received Human Ethics approval from the university of the first author.

The database holder sent a large number of emails $(15,000)$. The experiment was available for people to complete until the requisite number of completed surveys (1,500 in Australia and 1,500 in New Zealand) was received, which was approximately three days. At this time, the survey closed.

\footnotetext{
${ }^{12}$ Upon receipt of the email requesting participation, individuals received a link to the experiment. Completion of the experiment provided individuals with a code that allowed collection of the reward points.
} 
All respondents were required to complete the survey in order to receive their retail reward points, although for some questions (income, age, etc.), people could respond 'Prefer not to say'. We coded these as missing. When we required the subjects to have complete responses for all the demographic variables, we were left with 2,527 respondents, 1,266 (50.1\%) from New Zealand, and 1,261 (49.9\%) from Australia. We then considered the characteristics of the study participants separately by New Zealand and Australian respondents.

\section{Country Selection}

New Zealand and Australia are frequently utilised in cross-country studies, as they lend themselves to effective comparative studies. They are both successful southern-hemisphere Commonwealth countries with similar demographic profiles, social policy objectives and British colonial heritage (Marriott, 2010). The countries have parliamentary governments, are both OECD member countries, are geographically close and have close trade relationships.

This study does not compare between the two countries and instead uses the two countries together to examine for different responses to the same events. We use Australia and New Zealand, as they are sufficiently similar from an economic, social and legal perspective. For example, McLean (2003:14) claims that 'these two have more in common with one another than either has with any other country on the planet ... they are probably simply more alike than any other two separate nations' (2003:14); and suggests that:

There are strong personal and social affinities between the two peoples and close links by modern transport; both are liberal, moderate democracies, fortunate and successful states with a far-reaching network of co-operation between them; there are no divisive legacies of bitterness or wars: there is nothing of a racial, religious, ethical or linguistic character to provide any pretext for apart-ness.

\section{Characteristics of Survey Respondents}

The survey collected a range of demographic variables. This section discusses those that are most relevant to the analysis, together with the traditional variables of gender and age. We do not include tables outlining the variables, in the interests of space. However, details of respondents are available from the authors on request. The gender responses were $48 \% / 52 \%$ male/female in New Zealand and $46 \% / 54 \%$ in Australia. We received a good range of age responses, noting that we only requested responses from those aged over 18 . The survey has large numbers of European responses - New Zealand European in New Zealand and Australian European in Australia. As compared to census profiles, New Zealand Māori and Pasifika are under-represented in New Zealand. Asians have higher representation in Australia at $13.3 \%$ (approximately $7 \%$ of the Australian population identify with at least one Asian ethnicity) and lower representation in New Zealand at $4.6 \%$ (approximately $12 \%$ of the New Zealand population identify with at least one Asian ethnicity).

We grouped respondents into three professional groups. Nearly half (48.1\%) of Australian respondents have classified themselves as unskilled, as compared to $30.4 \%$ of New Zealanders. In the Manager/Professional category, New Zealand has greater representation at $38.6 \%$, compared to $24.3 \%$ for Australia. This aligns with other variables, which show that 
Australian respondents are younger and more receive welfare benefits than New Zealand respondents.

In both Australia and New Zealand, the main source of income is from wages and salaries: $58 \%$ in Australia and $67 \%$ in New Zealand. In Australia, 16\% of respondents reported receiving a pension while $17 \%$ of New Zealand respondents reported the same. New Zealand respondents reported that $12 \%$ per cent were self-employed, as compared to seven per cent of Australians. Only small proportions of people had no source of income, or income from capital, in both countries. We have a considerably higher proportion of people reporting as being on a benefit in Australia at $14.5 \%$ as compared to New Zealand at 3\%. We separate old-age pensions and other welfare benefits in this grouping. The proportion of the working age population (18-64 years of age) in receipt of welfare benefit is $18 \%$ in Australia (Australian Council of Social Services 2014) and 11\% in New Zealand (Ministry of Social Development 2014). Therefore, both countries are under-represented in the survey by individuals in receipt of welfare benefits.

\section{Social Dominance Orientation Scale}

The survey had 80 questions, but we do not include all the questions in this article. We positioned the SDO questions at the end of the study, after all the questions on perceptions of tax or welfare had been finished. We told respondents: 'we would now like to ask your views on a range of topics relating to groups within society. Please click on the response that best reflects your view'. The questions outlined in Appendix I followed.

The SDO scale is a widely used social psychological scale. It consists of 16 items, each scored from 1 (strongly disagree) to 7 (strongly agree). ${ }^{13}$ We divide the scale into two 8 -item sub-domains (Dominance and Egalitarianism). ${ }^{14}$

We calculate scores by taking the mean of the items for that score, after appropriate reverse coding for items asking 'negatively'. The two-factor solution for the SDO in our sample gave the same result - splitting the items into the same ones defined for Dominance and Egalitarianism - as reported in the literature. In our sample, the Cronbach's alpha for all 16 items was 0.890 (95\% CI: 0.883, 0.896), for the 8-item Egalitarianism score, Cronbach's alpha was $0.871(0.863,0.878)$, and for the 8-item Dominance score, alpha $=0.873(0.865$, $0.880)$.

Table 2 outlines the means and standard deviations for our sample.

(Insert Table 2 About Here)

\section{FINDINGS}

In order to address the question of whether people are likely to believe their own in-group is more or less likely to engage in a particular crime, we examine the likelihood that the

\footnotetext{
${ }^{13}$ For further detail, see Sidanius and Pratto (2001).

${ }^{14}$ For further detail, see Ho et al (2012).
} 
respondent thought a 'type' of person would be more or less likely to evade tax or engage in welfare fraud. We pose two scenario-based questions to respondents as follows:

(1) Tax Fraud Scenario. You read in the newspaper that someone has been caught evading tax. If you knew the following about them, do you think it is more or less likely that the person is guilty?

(2) Welfare Fraud Scenario. You read in the newspaper that someone has been caught committing welfare fraud. If you knew the following about them, do you think it is more or less likely that the person is guilty?

For each of the scenarios, we provided seven options:

1. The person did not have a job

2. The person owns their own home

3. The person is of Māori ethnicity

4. The person is a businessman

5. The person receives a welfare benefit

6. The person is an immigrant from the United Kingdom

7. The person is an immigrant from Tonga

We collected responses on a 7-point Likert scale from 1 (more likely) to 7 (less likely). We did not give any additional anchors with the exception of a mid-point anchor at 4 (undecided).

We selected these options due to expected stereotypes of particular types of people. The Māori group is included as Māori are the indigenous people of New Zealand and comprise approximately $15 \%$ of the population. Historically they have been the target of negative stereotypes (e.g. 'lazy, slovenly and inefficient and not able to cope with the strict time demands of the capitalist world'). ${ }^{15}$ As the indigenous Aboriginal population in Australia is around two per cent, we did not set out to investigate Aboriginal responses, as we believed it was unlikely that we would get sufficient responses to engage in meaningful analysis.

We used repeated measures analysis of variance to test whether the average 'likelihood of being guilty' differed by the seven different 'types' of people outlined above; whether there were differences by scenario; and whether the differences by person differed by scenario (the interaction effect). We use Bonferroni post-hoc tests to determine which 'types' of people differed from each other. Table 3 outlines the results of the overall analysis, which shows a significant difference by scenario, by person and a significant interaction.

\section{(Insert Table 3 About Here)}

The results of the analysis of both scenarios were difficult to interpret, therefore we analysed each scenario separately. The one-way ANOVA used is equivalent to a two-sample t-test. This is suitable for even very small sample sizes $(<15$, for example). As our sample sizes are at least 50 in every group, there is no problem with lack of power. The other assumption of

\footnotetext{
15 Te Ara The Encyclopedia of New Zealand. Story: European ideas about Māori. Retrieved from: http://www.teara.govt.nz/en/european-ideas-about-maori/page-6, 18 February 2017.
} 
the t-test is that the data are normally distributed. To deal with this possibility, we conducted non-parametric tests (Wilcoxon tests, the non-parametric equivalent to the t-test). The results remain the same. Table 4 reports the means by scenario and by person.

\section{(Insert Table 4 About Here)}

Table 4 shows that by ranking, respondents felt those least likely to engage in tax fraud were those who did not have a job, while the person most likely to engage in tax fraud was the businessman. These are expected responses, as it is reasonable to assume that someone who did not have a job was not in a position to evade tax (as they have no income). In a similar way, a businessman has the greatest opportunity to engage in tax fraud.

For welfare fraud, the person viewed as most likely to engage in welfare fraud is the person in receipt of welfare. The person viewed as least likely to engage in welfare fraud is the immigrant from the United Kingdom. As those who are eligible for welfare are those most likely to be in a position to take advantage of the scheme, these are also expected responses. Immigrants from the United Kingdom are less likely to be eligible for welfare payments in either New Zealand or Australia, so it is a valid assumption that they may be the group least likely to be able to engage in welfare fraud.

In order to examine the influence of in- and out-groups in this study, we investigated whether the respondent's choice differed by whether they were a similar or a dissimilar person. For both scenarios, we provided the Māori ethnicity option. Table 5 outlines the mean responses to these questions by Māori and non-Māori.

\section{(Insert Table 5 About Here)}

As can be seen in Table 5, when we asked Māori about a Māori person, they give a higher value than when we asked non-Māori about a Māori person. That is, Māori respondents believe that Māori are less likely to engage in tax and welfare fraud than non-Māori respondents. The mean differences are statistically significant for tax fraud and almost significant for welfare fraud.

The next group we examined was the businessman. We classified the in-group as men, who had identified in the manager/professional occupation grouping. Table 6 outlines these results.

\section{(Insert Table 6 About Here)}

For both scenarios, businessmen give people like them higher scores, that is, they believe they are less likely to engage in either crime, than non-businessmen. The difference in means is larger for tax fraud than for welfare fraud. This shows businessman respondents believe that they are less likely to commit these crimes than other people think they are.

The third group we examined was the group of respondents who were in receipt of welfare benefits. We identified these groups from those who responded that their sole source of income was from benefits. Table 7 reports these results.

(Insert Table 7 About Here) 
As with the other two groups, the in-group (i.e. those receiving welfare benefits) scored the person on a benefit more highly than respondents who had some other source of income did. That is, they perceived that the person receiving welfare benefits was less likely to be guilty than other respondents.

The next question we address is how does social dominance orientation affect this relationship between in- and out-groups, and their responses about the likelihood of who will engage in the financial fraud. To examine this, we fit General Linear Models to model the relationship between Group (Māori, Businessman and Welfare Recipient), Social Dominance Orientation (split into its two constituents Dominance and Egalitarianism), and the outcome variable (the likelihood of being guilty of tax or welfare fraud). For each model, the results gave p-values for Group and for whichever Social Dominance Orientation variable used, and parameter estimates, which gave the direction of the relationship. Table 8 outlines these results.

\section{(Insert Table 8 About Here)}

For each predictor (Dominance, Egalitarianism and Māori) and for each model (Tax Fraud or Welfare Fraud), the table gives the estimated coefficient, and its p-value. For Dominance and Egalitarianism, where the coefficient is positive, this means that as Dominance or Egalitarianism increases, the score increases, that is, the respondent believes the person is less likely to be guilty. Where the coefficient is negative, higher values of Dominance or Egalitarianism mean lower scores, that is, the person is more likely to be guilty. For the Māori variable, a negative coefficient means the score is lower for non-Māori than for Māori.

For Māori, Dominance and Egalitarianism were more important statistically than was the ethnicity of the respondent. The ethnicity was not significant, although there was always a trend towards statistical significance. This may have been due to the small sample size. The direction was always the same: Māori gave higher scores than non-Māori (negative coefficient, therefore less likely to be guilty). The coefficients of Dominance were negative, so that as a person's Dominance score increased, they would consider a Māori person more likely to be guilty. The reverse was true for Egalitarianism, that is, the more egalitarian the respondent was, the higher the score, i.e., the Māori person was less likely to be guilty.

Table 9 outlines the models for the businessmen. In these examples, non-Businessmen gave a lower score on average, that is, they perceived the businessmen as more likely to be guilty, than the businessmen did. This result was statistically significant for both scenarios. The coefficients for Dominance were positive for the tax fraud example and negative for the welfare fraud example. Therefore, for tax fraud, respondents with higher Dominance scores gave higher scores for tax fraud, that is, businessmen were less likely to be guilty. For the welfare fraud scenario, respondents with higher scores for Dominance gave a lower score, indicating that businessmen were more likely to be guilty. This finding is unexpected. However, to the extent that respondents believe that businessmen can structure their financial affairs more effectively than traditional employees, there may be a perception that they are receiving state benefits (such as working tax credits) if their incomes are artificially low. The media has reported examples of such behaviour in recent times. For Egalitarianism, the 
effect was similar for both scenarios - higher egalitarianism was associated with a lower score, that is, increased likelihood of being guilty.

\section{(Insert Table 9 About Here)}

Table 10 outlines Welfare recipients, our final example. There was no association between Dominance or Egalitarianism, and the likelihood of being guilty of welfare fraud. However, if the respondent was a welfare recipient, they scored the likelihood of guilt lower (i.e. more likely) than if the respondent was not a welfare recipient. There was a strong statistical relationship between Dominance (but not Egalitarianism) and the likelihood of being guilty of tax fraud. Again, higher values of Dominance were associated with lower scores (more likely to be guilty) and higher values of Egalitarianism were associated with higher scores (less likely to be guilty). In all situations, welfare recipients scored themselves higher (i.e. less likely to commit the crime) than non-welfare recipients scored them. For welfare recipients, all that matters is the in-group and out-group. Unlike the other two groups, dominance and egalitarianism is not important.

\section{(Insert Table 10 About Here) \\ DISCUSSION}

Cooper, Dacin and Palmer observe that fraud is not 'personal nor universal' and instead is 'situated in specific social and historical contexts' (2013:445). This was evident in the prejudice views held by our survey respondents. These views align with expected stereotypes: businessmen evade tax or people receiving welfare benefits engage in welfare fraud. When we examine views on the likelihood of 'who' will engage in tax or welfare fraud, we find different stereotypes among different groups.

The literature on prejudice, together with social dominance theory, suggests that affiliation with a group generates a more positive stereotype of that group. This is evident in the findings reported in this study. Our more detailed analysis of in- and out-groups (Māori and non-Māori, businessmen and non-businessmen, and recipients of welfare and non-recipients of welfare) showed a strong presence of preference for one's own group. In all cases, the ingroup believed that their own group was less likely to commit the crime - regardless of whether the crime was welfare or tax fraud - indicating the presence of the positive social identity suggested by social dominance theory.

We find evidence of prejudice towards Māori people among the respondents who scored high on SDO dominance measures, whereby these respondents considered that a person of Māori ethnicity was more likely to be guilty of tax or welfare fraud. The opposite was visible among respondents who scored high on SDO egalitarianism. However, we find that for those who scored highly on SDO dominance measures, they are more likely to think favourably about how businessmen will behave in relation to tax fraud (i.e. that they are less likely to engage in tax fraud), but more likely to engage in welfare fraud. We find a similar result with those who scored highly on SDO egalitarianism measures, whereby higher egalitarianism was associated with increased likelihood of committing either crime. This response for businessmen aligns with the inherent prejudice that is prevalent with welfare fraud. Those who score highly on SDO dominance measures are those who have agreed with 
statements suggesting that some groups of people are more worthy than others, that some groups of people should stay 'in their place', and that it is a good thing that some groups are at the top and others are at the bottom (among other questions). Thus, dominance is associated with superiority of certain groups and businessmen are likely to be a group that is more desirable and superior than other groups.

When investigating welfare fraud and welfare recipients, we find fewer associations with Dominance or Egalitarianism. However, we did find strong relationships with tax fraud, whereby higher Dominance was associated with perceptions that welfare recipients are more likely to be guilty and higher Egalitarianism was associated with perceptions that welfare recipients were less likely to be guilty.

The criminal justice system is more likely to apply harsh criminal sanctions against members of subordinate social groups than members of dominant social groups across a range of differentiating characteristics (Gross and Mauro, 1989; Baldus, Woodworth and Pulaski, 1990; Sidanius et. al, 2006). When minority groups with few resources, networks, or power receive support primarily from in-groups, then it is perhaps unsurprising that these groups receive less favourable treatment in the justice system. Other groups that have greater power, resources, and networks are also more likely to receive support from similar people or groups, who also have greater power, resources, and networks.

The professional field of tax is largely the domain of elites: accountants, lawyers and economists. Tax laws are complex, which facilitates exploitation by those sufficiently knowledgeable to minimise payment obligations. Those who are privileged are more likely to commit tax fraud: typically, the fraudster has the funds before the fraud occurs. ${ }^{16}$ This raises the potential for the embedding of practices when they benefit the interests of dominant groups (Chua, 1986) and act to reinforce privileged positions.

The results also suggest the presence of intergroup conflict. The literature predicts hostility towards the minority group, which is visible in the harsher treatment that welfare recipients receive in the investigation, prosecution and sentencing phases of the justice system. The presence of such in-groups and out-groups contributes to inequity, to the extent that preferences of the powerful do not extend beyond their own in-group.

Reference to the sociological literature reveals the status of welfare recipients as marginalised people. Fineman explains an often-accepted narrative when she writes 'we venerate the autonomous, independent, and self-sufficient individual as our ideal. We assume that anyone can cultivate these characteristics, consistent with our belief in the inherent equality of all members of our society, and we stigmatize those who do not' (Fineman, 2006:135). Moreover, we respect entrepreneurs and business owners, and hold in high esteem those who create jobs and 'contribute' to society - making excuses for their crimes when they are

\footnotetext{
${ }^{16}$ For example, when collection occurs, but payment to the government does not.
} 
exposed. ${ }^{17}$ This social construction of what is fraudulent activity facilitates and reinforces inand out-group preference and restricts meaningful social change.

We acknowledge the limitations of this study. While we targeted a representative sample of the New Zealand and Australian populations, we did not receive responses that entirely matched the populations based on census data. The main concern in this regard is the underrepresentation of ethnic minority groups that are among the lower socio-economic groups (e.g. Pasifika and Māori). We used the SDO scale as a framework to assess prejudice. This instrument has been widely tested and is highly reliable. However, we acknowledge that different results may arise with the use of a different instrument. In addition, we have only examined one explanatory variable, which is prejudice. There are multiple factors that affect views of crimes, of which prejudice is only one.

\section{CONCLUSION}

This study adds to the literature on in-groups and out-groups specific to tax and welfare fraud, as comparable crimes. The fundamental premise of social dominance theory is that societies minimise conflict by creating consensus on ideologies that promote the superiority of one group over others (Pratto et al, 1994). This is visible in the data and findings previously outlined. The results of our survey show that in-groups hold preferable views of their own in-groups. Thus, to the extent that groups with more power or status view their own group as superior, we are unlikely to see significant change to the current differences in treatment of tax and welfare fraudsters.

Walzer (1983), in his theory of justice, suggests that social goods (or bads) should not be distributed based on some arbitrary characteristic. In this case, the characteristic is whether the person is in receipt of a welfare benefit. If someone is situated in a group with greater or fewer resources or power, this should not result in a different treatment in the justice system. Nor should it allow for influence over the treatment of other groups. Individuals should receive equal treatment, unless treating them unequally produces a more equitable outcome. However, in the absence of direct, deliberate action to address the different treatments in the justice system, it is unlikely that meaningful change will occur.

This leads to the role of critical research. With reference to critical research, Chua (1986:621) observes that in order to highlight restrictive conditions, it is necessary to demonstrate that 'so-called objective and universal social laws are but products of particular forms of domination and ideology'. While Chua is discussing accounting, her statement is equally applicable to taxation. Chua continues to observe that in challenging the status quo 'social change may be initiated such that injustice and inequities may be corrected' (1986:621). Herein lies the role of critical tax researchers.

In the same way that accounting researchers have identified that accounting theories are 'normative and value-laden in that they usually mask a conservative ideological bias', tax

\footnotetext{
${ }^{17}$ Analysis by the authors of sentencing decisions of serious white-collar crime in New Zealand shows that the 'good character' of the offenders was a factor in reducing the sentence in $56 \%$ of cases.
} 
theories and practice may be equally accused. There is considerable capacity for critical tax research to have greater involvement in highlighting the potential for privileged individuals to receive privileged treatment in the justice system when committing 'privileged crimes' (Tinker, Merino and Neimark, 1982:167).

While this study focuses on tax, considerations for the accounting profession may be drawn. As noted in the previous section, accountants are one of the key groups that comprise the broad tax discipline. The in-group of accountants, which operates within an overarching ethical framework, may have an ethical duty to challenge behaviours whereby minority groups are the subject of discrimination. As argued by Bruna and Bazin 'supporting the Other...is an ethical duty' (2017:4). A further consideration for accountants relates to the finding of strong in-group preference. This preference is relevant for a profession that retains elements of self-regulation, as this study suggests that accountants are likely to have a more favourable view of accountants than other out-groups. This preference may further extend to other activities frequently provided in-house by accounting professional bodies, such as professional development and education.

Where powerful groups believe in the superiority of other similar powerful groups, this reinforces the status quo. This article has used the example of the different treatment of tax and welfare fraud in the justice systems of New Zealand and Australia to highlight prejudice and privilege. Given the findings in this study, there are significant societal issues that tax scholars can, and arguably should, be challenging. This study highlights the potential for critical tax research to challenge the privileged position that tax commands in society and to provide robust evidence-based challenges to the status quo. While tax avoidance by multinational enterprises has received greater focus in recent years, many of the discriminatory practices that exist at an operational level remain unchallenged. In New Zealand, universities have 'a role as critic and conscience of society' 18 and tax researchers are not heeding this obligation to the extent that critical tax research as a discipline in Australasia does not tackle issues of social justice. We follow the example of Lehman, Annisette and Agyemang (2013) in relation to critical accounting research, and call for critical tax researchers to assist in giving voice to the marginalised.

\footnotetext{
${ }^{18}$ Education Act 1989, s 4(a)(v).
} 


\section{REFERENCES}

Australian Institute of Criminology. (1986), "How the Public Sees Crime: An Australian survey", Trends \& Issues in Crime and Criminal Justice, Vol 2, pp. 1-6.

Baldus, D.C., Woodworth, G., and Pulaski, C.A. (1990), Equal Justice and the Death Penalty: A legal and empirical analysis, Northeastern University Press, Boston, MA.

Blumberg, Grace. (1971), "Sexism in the Code: A comparative study of income taxation of working wives and mothers", Buffalo Law Review, Issue 1, pp. 49-98.

Boden, R., Killian, S., Mulligan, E., and Oats, L. (2010), "Editorial: Critical Perspectives on Taxation", Critical Perspectives on Accounting, Vol 21, pp. 541-544.

Boden, R., Childs, M., and Wild, W. (1995), "Pride and Prejudice: Women, tax and citizenship", Critical Perspectives on Accounting, Vol 6, pp. 125-148.

Bright, R.A. (1978), "Dole Bludgers or Tax Dodgers: Who is the deviant?" in P. Wilson and J. Braithwaite, eds., Two Faces of Deviance: Crimes of the powerless and powerful. St Lucia: University of Queensland Press.

Brown, Dorothy, A. (2007), "Race and Class Matters", Columbia Law Review, Vol 107, No 3, pp. 790-831.

Brown, R. (1995), Prejudice: Its social psychology, Blackwell, Oxford.

Bruna, M.G., and Bazin, Y. (2017), “Answering Levinas' Call in Organization Studies”, European Management Review, DOI: 10.1111/emre.12137.

Cain, Patricia. (1991), "Same-Sex Couples and the Federal Tax Laws", Law \& Sexuality: A review of lesbian and gay legal issues", Vol 1, pp. 97-132.

Chua, Wai Fong. (1986), "Radical Developments in Accounting Thought", The Accounting Review, Vol 61, No 4, pp. 601-632.

Cook, D. (1989), Rich Law, Poor Law: Differential response to tax and supplementary benefit fraud, Open University Press, Milton Keynes.

Cook, D. (2006), Criminal and Social Justice, Sage Publications, London.

Cooper, D.J., Dacin, T., and Palmer, D. (2013), "Editorial: Fraud in accounting, organizations and society: Extending the boundaries of research", Accounting, Organizations and Society, Vol 38, p. 440-457.

Cowell, Frank, A. (1985), “Tax Evasion with Labour Income”, Journal of Public Economics, Vol 26, pp. 19-34.

Croall, H. (2001), Understanding White Collar Crime, Open University Press, Buckingham.

Croall, H. (2011), Crime and Society in Britain, $2^{\text {nd }}$ Edition, Pearson Education, Harlow, Essex.

Cullen, F.T., Link, B.G., and Polanzi, C.W. (1982), "The Seriousness of Crime Revisited", Criminology, Vol 20, No 1, pp. 83-102.

Darley, J.M., and Gross, P.H. (2000), “A Hypothesis-Confirming Bias in Labeling Effects", in C. Stangor (ed.), Stereotypes and Prejudice: Essential Readings, Taylor and Francis, Philadelphia.

Dillard, Jesse, F. (1991), “Accounting as a Critical Social Science”, Accounting, Auditing \& Accountability Journal, Vol 4, No 1, pp. 8-28.

Duckitt, J. (1992), The Social Psychology of Prejudice, Praeger, New York.

Duckitt, J. (2001), "A Dual-Process Cognitive-Motivational Theory of Ideology and Prejudice”, Advances in Experimental Social Psychology, Vol 33, pp.41-113.

Duckitt, J., Wagner, C., De Plessis, I., and Birum, I. (2002), "The Psychological Bases of Ideology and Prejudice: Testing a dual-process model", Journal of Personality and Social Psychology, Vol 83, No 1, pp. 75-93. 
Duckitt, J. and Sibley, C. (2010), "Right-Wing Authoritarianism and Social Dominance Orientation Differentially Moderate Intergroup Effects on Prejudice", European Journal of Personality, Vol 24, pp. 583-601.

Evans, M. and Kelley, J. (2001), "Are Tax Cheating and Welfare Fraud Wrong? Public opinion in 29 nations", Australian Social Monitor, Vol 3, No 4, pp. 93-102.

Falkinger, Josef. (1988), "Tax Evasion and Equity: A theoretical analysis", Public Finance, Vol 43, No 3, pp. 388-395.

Farrar, J. (2011), “Tax Fairness in Canadian Government Budgets: How fair is 'fair'?", Critical Perspectives on Accounting, Vol 22, pp. 365-375.

Fineman, M.A. (2006), Dependency and Social Debt, in D Grusky and R Kanbur (eds) Poverty and Inequality. Stanford: Stanford University Press.

Fishbein, M., and Ajzen, I. (1975), Belief, Attitude, Intention, and Behavior: An introduction to theory and research, Addison-Wesley Publishing Company, Reading, MA.

Forest, Adam, and Sheffrin, Steven. (2002), "Complexity and Compliance: an empirical investigation", National Tax Journal, Vol 55, No 1, pp. 75-90.

Gracia, Louise, and Oats, Lynne. (2012), "Boundary Work and Tax Regulation: A Bourdieusian view", Accounting, Organizations and Society, Vol 37, pp. 304-321.

Gross, S.R., and Mauro, R. (1989), Death and Discrimination: Racial disparities in capital sentencing, Northeastern University Press, Boston, MA.

Grown, Caren, and Valodia, Imraan. (2010), Taxation and Gender Equity: A comparative analysis of direct and indirect taxes in developing and developed countries, Routledge, London.

Gupta, R. (2006), "Perceptions of Tax Evasion as a Crime: Evidence from New Zealand", New Zealand Journal of Taxation Law and Policy, Vol 12, pp. 199-219.

Gustafson, K. (2009), "The Criminalization of Poverty", Journal of Criminal Law \& Criminology, Vol 99, No 3, pp. 643-716.

Hagan, J., Nagel, I., and Albonetti, C. (1980), "The Differential Sentencing of White-Collar Offenders in Ten Federal District Courts", American Sociological Association, Vol 45, No 2, pp. 802-820.

Hamilton, D.L., and Gifford, R.K. (2000), "Illusory Correlation in Interpersonal Perception: A cognitive basis of stereotypic judgments", in C. Stangor (ed.), Stereotypes and Prejudice: Essential Readings, Taylor and Francis, Philadelphia.

Ho, A., Sidanius, J., Pratto, F., Levin, S., Thomsen, L., Kteily, N. and Sheehy-Skeffington, J. (2012), "Social Dominance Orientation: Revisiting the structure and function of a variable predicting social and political attitudes", Personality and Social Psychology Bulletin, Vol 38, No 5, pp. 583-606.

Hudson, B. (1993), Penal Policy and Social Justice, MacMillan Press, Basingstoke.

Infanti, Anthony, C. (2008), “Tax Equity”, Buffalo Law Review, Vol 55, pp. 1191-1260.

Inland Revenue. (2016), Annual Report 2015/16, Inland Revenue, Wellington.

Karlinsky, S., Burton, H., and Blanthorne, C. (2004), "Perceptions of Tax Evasion as a Crime", eJournal of Tax Research, Vol 2, No 2, pp. 226-240.

Knauer, Nancy, J. (1998), "Heteronormativity and Federal Tax Policy", West Virginia Law Review, Issue 1, pp. 129-234.

Knauer, Nancy, J. (2014), “Critical Tax Policy: A pathway to reform?", Northwestern Journal of Law \& Social Policy, Vol 9, No 2, pp. 206-263.

Lehman, Cheryl, R., Annisette, Marcia, and Agyemang, Gloria. (2013), "Immigration and Neo-Liberalism: Three stories and counter accounts", APIRA 2013, Ref K184. Retrieved from: http://www.apira2013.org/proceedings/pdfs/K184.pdf, 19 February 2017.

Lehman, Cheryl, R., and Okcabol, Fahrettin. (2005), "Accounting for Crime", Critical Perspectives on Accounting, Vol 16, pp. 613-639. 
Lindley, J., Jorna, P., and Smith, R. (2010), Fraud Against the Commonwealth 2009-2010 Annual Report to Government, Australian Institute of Criminology, Canberra.

Livingston, Michael, A. (2002), "Women, Poverty and the Tax Code: A tale of theory and practice", Journal of Gender, Race and Justice, Issue 2, pp. 327-338.

Locke, V. and Johnston, L. (2001), "Stereotyping and Prejudice: A social cognitive approach", in Augoustinos, M. and Reynolds, K.J. (eds.), Understanding Prejudice, Racism, and Social Conflict, Sage Publications, London.

Marriott, L. (2010), The Politics of Retirement Savings Taxation: A Trans-Tasman Comparison, $\mathrm{CCH}$, Sydney.

Marriott, L. (2013), "Justice and the Justice System: A comparison of tax evasion and welfare fraud in Australasia", Griffith Law Review, Vol 22, No 2, pp. 403-429.

Marriott, L. (2014), "Unpaid Tax and Overpaid Welfare: A comparison of debt recovery approaches in New Zealand", New Zealand Journal of Taxation, Law and Policy, Vol 20, No 1, pp.46-70.

Marston, G., and Walsh, T. (2008), "A Case of Misrepresentation: Social security fraud and the criminal justice system in Australia", Griffith Law Review, Vol 17, No 1, pp. 285-300.

McIntosh, R.K., and Veal, J.A. (2001), "Tax Evasion and New Zealanders' Attitudes towards It", New Zealand Journal of Taxation Law and Policy, Vol 7, pp. 80-110.

McLean, D. (2003), The Prickly Pair: Making nationalism in Australia and New Zealand, University of Otago Press, Dunedin.

Ministry of Social Development. (2016), Annual Report 2015/16, Ministry of Social Development, Wellington.

Mitchell, Austin, Sikka, Prem, and Willmott, Hugh. (2001), "Policing Knowledge by Invoking the Law: Critical accounting and the politics of dissemination", Critical Perspectives on Accounting, Vol 12, pp.527-555.

Morales, Jérémy, and Sponem, Samuel. (2017), "You too can have a critical perspective! 25 years of Critical Perspectives on Accounting", Critical Perspectives on Accounting, Vol 43, pp. 149-166.

Moran, Beverly, I., and Whitford, William. (1996), "A Black Critique of the Internal Revenue Code", Wisconsin Law Review, Issue 4, pp. 751-820.

Mumford, Ann. (2009), Tax Policy, Women and the Law: UK and Comparative Perspectives, Cambridge University Press, Cambridge.

Nelken, D. (1997), "White-Collar Crime”, in Maguire, M. Morgan, R. and Reiner, R. (eds.), The Oxford Handbook of Criminology, $2^{\text {nd }}$ Edition, Oxford University Press, Oxford.

Orviska, M and Hudson, J. (2002), "Tax Evasion, Civic Duty and the Law Abiding Citizen", European Journal of Political Economy, Vol 19, pp. 82-103.

Parker, Lee, D. (2011), "Twenty-One Years of Social and Environmental Accountability Research: A coming of age", Accounting Forum, Vol 35, pp. 1-10.

Piketty, Thomas. (2014), Capital in the Twenty-First Century, Harvard University Press, Boston.

Pratto, F., Sidanius, J., and Levin, S. (2006), "Social Dominance Theory and the Dynamics of Intergroup Relations: Taking stock and looking forward", European Review of Social Psychology, Vol 17, No 1, pp. 271-320.

Pratto, F., Sidanius, J., Stallworth, L. and Malle, B. (1994), "Social Dominance Orientation: A personality variable predicting social and political attitudes", Journal of Personality and Social Psychology, Vol 67, No 4, pp. 741-763.

Prenzler, T. (2010), "Detecting and Preventing Welfare Fraud", Trends \& Issues in Crime and Criminal Justice, Vol 418, pp. 1-6.

Reiman, J., and Leighton, R. (2013), The Rich get Richer and the Poor get Prison: Ideology, class, and criminal justice, $10^{\text {th }}$ Edition, Pearson, Boston. 
Sibley, C., Robertson, A. and Kirkwood, S. (2005), "Pakeha Attitudes toward the Symbolic and Resource-specific Aspects of Bicultural Policy in New Zealand: The legitimizing role of collective guilt for historical injustices", New Zealand Journal of Psychology, Vol 34, No 3, pp. 171-180.

Sidanius, J., Mitchell, M., Haley, H., and Navarette, C. (2006), "Support for Harsh Criminal Sanctions and Criminal Justice Beliefs: A social dominance perspective", Social Justice Research, Vol 19, No 4, pp. 433-449.

Sidanius, J. and Pratto, F. (1999), Social Dominance: An intergroup theory of social hierarchy and oppression, Cambridge University Press, Cambridge.

Sidanius, J., Pratto, F., van Laar, C., and Levin S. (2004), "Social Dominance Theory: Its agenda and method", Political Psychology, Vol 25, No 6, pp. 845-880.

Smith, G., Button, M., Johnston, L., and Frimpong, K. (2011), Studying Fraud as White Collar Crime, Palgrave MacMillan, Basingstoke.

Spicer, Michael, W., and Becker, Lee, A. (1980), "Fiscal Inequity and Tax Evasion: An Experimental Approach", National Tax Journal, Vol 33, No 2, 171-176.

Spicer, Michael, W., and Lundstedt, S.G. (1976) "Understanding Tax Evasion", Public Finance, Vol 31, No 2, pp. 295-305.

Sutherland, E.H. (1940), "White Collar Criminality", American Sociological Review, Vol 5, pp. 1-12.

Sutherland, E.H. (1949), White Collar Crime, Holt, Reinhart and Winston, New York.

Terry, D.J., Hogg, M.A., and Blackwood, L. (2001), "Prejudiced Attitudes, Group Norms, and Discriminatory Behaviour", in Augoustinos, M. and Reynolds, K.J. (eds.), Understanding Prejudice, Racism, and Social Conflict, Sage Publications, London.

Tinker, Anthony, M., Merino, Barbara, D., and Neimark, Marilyn, Dale. (1982), "The Normative Origins of Positive Theories: Ideology and accounting thought", Accounting, Organizations and Society, Vol 7, No 2, pp. 167-200.

Tuck, Penelope. (2010), "The Emergence of the Tax Official into a T-Shaped Knowledge Expert", Critical Perspectives on Accounting, Vol 21, No 7, pp. 584-596.

Wacquant, L. (2009), Punishing the Poor: The neoliberal government of social insecurity, Duke University Press, Durham.

Wallschutzky, Ian, G. (1988), The Effects of Tax Reform on Tax Evasion, Australian Tax Research Foundation, Sydney.

Walzer, M. (1983), Spheres of Justice: A defense of pluralism and equality, Basic Books, New York.

Weisburd, D., Wheeler, S., Waring, E., and Bode, N. (1991), Crimes of the Middle Classes: White-collar offenders in the federal courts, Yale University Press, New Haven. 


\section{Appendix I: Social Dominance Orientation Questions}

\begin{tabular}{|c|c|c|}
\hline & Question & Category \\
\hline 1 & All groups should be given an equal chance in life & Egalitarianism \\
\hline 2 & Some groups of people are just more worthy than others & Dominance \\
\hline 3 & Group equality should be our ideal & Egalitarianism \\
\hline 4 & $\begin{array}{l}\text { In getting what your group wants, it is sometimes necessary to } \\
\text { use force against other groups }\end{array}$ & Dominance \\
\hline 5 & $\begin{array}{l}\text { We should do what we can to equalise conditions for different } \\
\text { groups }\end{array}$ & Egalitarianism \\
\hline 6 & $\begin{array}{l}\text { It's OK if some groups have more of a chance in life than } \\
\text { others }\end{array}$ & Dominance \\
\hline 7 & We should increase social equality & Egalitarianism \\
\hline 8 & $\begin{array}{l}\text { To get ahead in life, it is sometimes necessary to step on other } \\
\text { groups }\end{array}$ & Dominance \\
\hline 9 & $\begin{array}{l}\text { We would have fewer problems if we treated groups more } \\
\text { equally }\end{array}$ & Egalitarianism \\
\hline 10 & $\begin{array}{l}\text { If certain groups of people stayed in their place, we would } \\
\text { have fewer problems }\end{array}$ & Dominance \\
\hline 11 & We should strive to make incomes more equal & Egalitarianism \\
\hline 12 & $\begin{array}{l}\text { It's probably a good thing that certain groups are at the top } \\
\text { and other groups are at the bottom }\end{array}$ & Dominance \\
\hline 13 & No one group should dominate in society & Egalitarianism \\
\hline 14 & Inferior groups should stay in their place & Dominance \\
\hline 15 & Sometimes other groups must be kept in their place & Dominance \\
\hline 16 & It would be good if all groups could be equal & Egalitarianism \\
\hline
\end{tabular}


TABLES

Table 1: Similarities and Differences in Tax Fraud and Welfare Fraud

\begin{tabular}{|l|l|l|}
\hline & Tax Fraud & Welfare Fraud \\
\hline Intent & Deliberate fraud & Deliberate fraud \\
\hline How measured & Quantifiable & Quantifiable \\
\hline Victim & The state and society & The state and society \\
\hline Outcome & Fewer resources for the state & Fewer resources for the state \\
\hline Impact & Significant & Moderate $^{1}$ \\
\hline Activity & $\begin{array}{l}\text { Not paying funds legally due to the } \\
\text { state }\end{array}$ & $\begin{array}{l}\text { Taking more funds from the state than } \\
\text { legally entitled }\end{array}$ \\
\hline
\end{tabular}

Table 2: Means and Standard Deviations for Sample

\begin{tabular}{|l|r|r|r|r|r|}
\hline & Number & \multicolumn{1}{c|}{ Minimum } & Maximum & \multicolumn{1}{c|}{ Mean } & \multicolumn{1}{c|}{ Std. Deviation } \\
\hline Dominance & 2527 & 1.00 & 7.00 & 2.8265 & 1.20304 \\
\hline Egalitarianism & 2527 & 1.00 & 7.00 & 5.3705 & 1.04556 \\
\hline
\end{tabular}

Table 3: Overall analysis (Wilks' Lambda)

\begin{tabular}{|l|l|l|l|l|l|}
\hline & Value & F & Hypothesis df & Error df & Sig \\
\hline Scenario & .942 & 154.811 & 1.000 & 2526.000 & .000 \\
\hline Person & .645 & 231.415 & 6.000 & 2521.000 & .000 \\
\hline Scenario*Person & .690 & 188.693 & 6.000 & 2521.000 & .000 \\
\hline
\end{tabular}

Table 4: Means by Scenario and Person

\begin{tabular}{|c|c|c|c|c|}
\hline \multicolumn{4}{|c|}{ Tax Evasion Scenario } & \multirow[b]{2}{*}{ Maximum } \\
\hline Person & Mean & Std. Deviation & Minimum & \\
\hline 1. No job & 4.049 & 1.765 & 1 & 7 \\
\hline 2. Home owner & 3.498 & 1.436 & 1 & 7 \\
\hline 3. Māori & 3.825 & 1.293 & 1 & 7 \\
\hline 4. Businessman & 2.550 & 1.354 & 1 & 7 \\
\hline 5. On welfare & 3.450 & 1.607 & 1 & 7 \\
\hline
\end{tabular}

\footnotetext{
${ }^{1}$ For example, all forms of detected tax evasion in New Zealand in 2015/16 was reported as NZ\$1.2 billion, while detected welfare fraud in the same period was NZ\$24 million.
} 


\begin{tabular}{|l|l|l|l|l|}
\hline 6. From UK & 3.756 & 1.314 & 1 & 7 \\
\hline 7. From Tonga & 3.767 & 1.306 & 1 & 7 \\
\hline Welfare Fraud Scenario & 2.850 & 1.619 & 1 & 7 \\
\hline 1. No job & 3.793 & 1.647 & 1 & 7 \\
\hline 2. Home owner & 3.519 & 1.277 & 1 & 7 \\
\hline 3. Māori & 3.541 & 1.813 & 1 & 7 \\
\hline 4. Businessman & 2.644 & 1.448 & 1 & 7 \\
\hline 5. On welfare & 3.805 & 1.312 & 1 & 7 \\
\hline 6. From UK & 3.612 & 1.291 & 1 & 7 \\
\hline 7. From Tonga & & & & \\
\hline
\end{tabular}

Table 5: Responses by Māori and Non-Māori

\begin{tabular}{|l|l|l|l|}
\hline Mãori? & & Tax Evasion & Welfare Fraud \\
\hline No & Mean & 3.8181 & 3.5121 \\
\hline & Number & 2474 & 2474 \\
\hline Yes & Std. Deviation & 1.28227 & 1.27214 \\
\hline & Mean & 4.1698 & 3.8491 \\
\hline & Number & 53 & 53 \\
\hline Total & Std. Deviation & 1.68404 & 1.47278 \\
\hline & Mean & 3.8255 & 3.5192 \\
\hline & Number & 2527 & 2527 \\
\hline ANOVA & Std. Deviation & 1.29253 & 1.27725 \\
\hline & F (1,2525) & 3.846 & 3.615 \\
\hline Wilcoxon p-value & p-value & 0.050 & 0.057 \\
\hline
\end{tabular}

Table 6: Responses by Businessman and Non-Businessman

\begin{tabular}{|l|l|l|l|}
\hline Businessman? & & Tax Evasion & Welfare Fraud \\
\hline No & Mean & 2.5024 & 3.5024 \\
\hline & Number & 2122 & 2122 \\
\hline & Std. Deviation & 1.34842 & 1.83096 \\
\hline Yes & Mean & 2.8000 & 3.7407 \\
\hline & Number & 405 & 405 \\
\hline
\end{tabular}




\begin{tabular}{|l|l|l|l|}
\hline & Std. Deviation & 1.35960 & 1.70597 \\
\hline Total & Mean & 2.5501 & 3.5406 \\
\hline & Number & 2527 & 2527 \\
\hline & Std. Deviation & 1.35436 & 1.81330 \\
\hline ANOVA & F (1,2525) & 16.527 & 5.889 \\
\hline & p-value & $<0.0005$ & 0.015 \\
\hline Wilcoxon p-value & & $<0.0005$ & 0.010 \\
\hline
\end{tabular}

Table 7: Responses by Welfare Recipients

\begin{tabular}{|l|l|l|l|}
\hline Welfare Recipient? & & Tax Evasion & Welfare Fraud \\
\hline No & Mean & 3.426 & 2.6216 \\
\hline & Number & 2310 & 2310 \\
\hline & Std. Deviation & 1.60780 & 1.44081 \\
\hline Yes & Mean & 3.7051 & 2.8802 \\
\hline & Number & 217 & 217 \\
\hline & Std. Deviation & 1.57692 & 1.50136 \\
\hline Total & Mean & 3.4499 & 2.6438 \\
\hline & Number & 2527 & 2527 \\
\hline & Std. Deviation & 1.60677 & 1.44762 \\
\hline ANOVA & F (1, 2525) & 5.997 & 6.341 \\
\hline & p-value & 0.014 & 0.012 \\
\hline Wilcoxon p-value & & 0.009 & 0.012 \\
\hline
\end{tabular}

Table 8: Models for Māori

\begin{tabular}{|l|l|l|}
\hline Predictor & Tax Evasion Coefficient, p-value & Welfare Fraud Coefficient, p-value \\
\hline Dominance & $-0.154, \mathrm{p}<0.0005$ & $-0.107, \mathrm{p}<0.0005$ \\
\hline Egalitarianism & $0.056, \mathrm{p}=0.038$ & $0.046, \mathrm{p}=0.085$ \\
\hline Māori (yes/no) & $-0.309, \mathrm{p}=0.081$ & $-0.305, \mathrm{p}=0.083$ \\
\hline
\end{tabular}

Table 9: Models for Businessmen

\begin{tabular}{|l|l|l|}
\hline Predictor & $\begin{array}{l}\text { Tax Evasion Coefficient, p- } \\
\text { value }\end{array}$ & Welfare Fraud Coefficient, p-value \\
\hline
\end{tabular}




\begin{tabular}{|l|l|l|}
\hline Dominance & $0.069, \mathrm{p}=0.005$ & $-0.158, \mathrm{p}<0.0005$ \\
\hline Egalitarianism & $-0.163, \mathrm{p}<0.0005$ & $-0.139, \mathrm{p}<0.0005$ \\
\hline Businessman (yes/no) & $-0.262, \mathrm{p}<0.0005$ & $-0.211, \mathrm{p}=0.032$ \\
\hline
\end{tabular}

Table 10: Models for Welfare Recipients

\begin{tabular}{|l|l|l|}
\hline Predictor & $\begin{array}{l}\text { Tax Evasion Coefficient, } \mathbf{p} \text { - } \\
\text { value }\end{array}$ & Welfare Fraud Coefficient, $\mathbf{p}$-value \\
\hline Dominance & $-0.184, \mathrm{p}<0.0005$ & $0.018, \mathrm{p}=0.490$ \\
\hline Egalitarianism & $0.024, \mathrm{p}=0.470$ & $-0.003, \mathrm{p}=0.915$ \\
\hline Welfare recipient (yes/no) & $-0.274, \mathrm{p}=0.015$ & $-0.259, \mathrm{p}=0.012$ \\
\hline
\end{tabular}




\section{SOCIAL INEQUITY, TAXES AND WELFARE IN AUSTRALASIA ${ }^{1}$}

Purpose: The major aims of this study are to highlight, challenge and explain the inequitable treatment of tax and welfare fraudsters in the criminal justice systems of Australia and New Zealand. We offer prejudice by way of explanation and suggest that it is also prejudice that restricts the implementation of more equitable processes. A second objective of the study is to highlight the importance of critical tax research as an instrument to agitate for social change.

Design / Methodology / Approach: A survey captures 3,000 respondents' perceptions of the likelihood that different 'types' of people will commit welfare or tax fraud. Using the social dominance theoretical frameworktheory, we investigate the extent to which prejudice impacts on attitudes towards those who engageengaged in these fraudulent activities.

Findings: We find the presence of traditional stereotypes, such as the perception that businessmen are more likely to commit tax fraud and people receiving welfare assistance are more likely to commit fraud. We also find strong preferences towards respondents' own ingroup, whereby businessmen, Māori, and people receiving welfare assistance believed their own group was less likely to commit either crime.

Value: The study highlights the difficulty of social change in the presence of strong in-group preference and prejudice. Where minority groups have few resources, networks or power and receive support primarily from members of the same group, practices in the justice system that are detrimental to these groups are unlikely to receive the requisite attention needed to ehange embedded discrimination. Cognisance of in-group preference is relevant to the accounting profession where elements of self-regulation remain. In-group preferences may impact on services provided, as well as professional development and education.

Social Implications: Where in-group preference exists among those who are influential in eonstructing and enforeingconstruct and enforce the rules relating to investigations, prosecutions and sentencing of tax and welfare fraudhold more favourable attitudes towards their own in-group, it is perhaps unsurprising that welfare recipients attract less societal support than other groups who are supported byhave support from their own in-groups that have greater power, resources and influence.

Keywords: tax evasion; welfare fraud; prejudice; social dominance; inequity

\section{INTRODUCTION}

Like accounting, tax is not just about reporting and monitoring; it is more than a set of rules to determine who should pay what in certain circumstances. Instead, it is a social

\footnotetext{
${ }^{1}$ The authors are grateful for the constructive feedback and guidance provided by two anonymous reviewers and the editors in the publication of this article.
} 
construction compiled by the state, in conjunction with professional bodies and interested entities. As noted in Chua's seminal article (1986:601), accounting is a 'common set of philosophical assumptions about knowledge, the empirical world, and the relationship between theory and practice'. The same observation may be made of taxation. The taxation discipline has its own rules and generally understood ways of doing things. Moreover, it has its own generally accepted processes for addressing transgressions from these rules and regulations. Other social institutions, such as welfare agencies, have similarly understood and taken for granted rules pertaining to behaviours and sanctions for wrongdoings.

This study uses the field of taxation to highlight and challenge issues of inequity and social justice. It does this by illustrating how the conceptually similar crimes of tax evasion and welfare fraud result in different outcomes in the justice system. Table 1 outlines the similarities and differences in the two crimes.

\section{(Insert Table 1 About Here)}

Table 1 shows a number of similarities in the two crimes: they are deliberate; they have the same victim; and they have the same outcome. Moreover, both are quantifiable in the form of the economic harm that results from the activity. While tax evasion is the usual description attached to tax non-compliance, in order that the conventional labels attached to the offences do not detract from the following analysis and discussion, both activities will be referred to as 'fraud' for the remainder of this article.

Table 1 also shows the two key differences in the crimes. Tax fraud has considerably more economic significance than welfare fraud - 50 times the magnitude in New Zealand in 2015/16 (Inland Revenue, 2016; Ministry of Social Development, 2016). However, Table 1 does not show the privilege shown to tax fraudsters as compared to welfare fraudsters. Thus, the first aim of this study is This study uses the tax and welfare systems to illustrate how those with greater resources and influence in society may expect to receive preferential treatment when compared to those who are less powerful in society, using the tax and welfare systems for illustrative purposes. The aim extends to This illustration is one of the primary aims of this study. The other aims of the study are to-challenge this preferential treatment and explain why these differences continue to exist in a society that is increasingly accepting that unequal treatment of individuals is undesirable.

This study explores the role of prejudice as an explanation for the differences in treatment of tax and welfare fraudsters, using a social dominance theoretical framework. Prejudice is a concept used by secial seientistssocial scientists use to both-describe and understand intergroup conflicts that occur in society (Duckitt, 1992). Social dominance theory highlights the presence of prejudice, as it suggests that individuals create social groups that promote hierarchies. The theory captures the extent to which individuals prefer societal relations to be equal or whether their preference is for their own group to dominate.

Extending Mitchell, Sikka and Willmott's (2001:528) encouragement for accounting scholars to more directly intervene in worldly affairs and 'report "inconvenient facts" to a wider public', the genesis of our study is the different treatments of welfare and tax fraudsters in New Zealand and Australia. In the study, we examine in- and out-groups and the extent to 
which individuals believe that their own group is more or less likely to commit either tax or welfare fraud. We do this by reporting on results from a large survey with 3,000 respondents.

We find strong evidence of the presence of social dominance along with traditional stereotyping. In doing so, we find in-group preference: individuals believe their own in-group is less likely to commit the crimes of tax or welfare fraud than other groups. This finding suggests that it may be difficult to change the extant inequitable treatment currently afforded to welfare fraudsters, as those with the most power and influence are, adopting social dominance theory, most likely to favour their own in-group.

The study has a second objective, which is to make a case for more critical tax research. A Special Issue of critical tax research in 2010 noted that 'tax has not received the intellectual attention it deserves from accounting scholars and indeed is often marginalized by other apposite fields of enquiry such as political science, law and social policy' (Boden, Killian, Mulligan and Oats, 2010). ${ }^{2}$ This is despite the significance of tax to society. Thus, we pursue Dillard's claim that through an examination of contemporary social, economic and political issues, means for producing a critique are proposed that potentially could assist in a rational evaluation of ... social arrangements and motivate changes in practices and policies deemed irrational and oppressive' (1991:9).

The structure of this article is as follows. First, we establish the problem in section two by providing an outline of the literature that has investigated how those with greater or fewer resources are treated differently in society. We use white- and blue-collar crime for definitional purposes. We follow this with data to illustrate the different treatment of tax and welfare fraudsters in both the New Zealand and Australian justice systems. Section two also provides an outline of the concept of prejudice, used for explanatory purposes in this study. Section three engages with the critical tax research on inequity. Section four provides an outline of the theoretical framework used in the study: social dominance theory. Section five follows, which outlines the research questions, describes the research design and provides the characteristics of the survey respondents. Section six describes the research findings, which show that in-groups support similar in-groups. Section seven engages in a discussion of the issue whereby privileged in-groups hold sufficient power to maintain the status quo, resulting in a situation where we are unlikely to see outcomes improve for those who are least powerful in society. Section eight draws conclusions where, given the findings of the study, we highlight the importance of scholarly engagement in the field of tax.

\footnotetext{
${ }^{2}$ We do not suggest that there is no critical tax research or that the critical tax research community is not engaging in excellent work. Recent activities such as the dedication of a Special Issue of Critical Perspectives on Accounting to taxation issues (2010, Issue 21, Volume 7) is one example. However, older valuable studies also exist, such as Boden, Childs and Wild (1995). However, the field remains less developed when compared to progress in accounting. There are also fewer tax scholars than accounting scholars, which impacts on the quantity of critical tax publications.
} 


\section{BACKGROUND}

The background section serves two purposes. It moves from the general to the specific, starting with the existing literature on the different treatment of individuals in different socioeconomic groups in the justice system. This serves to establish the generally accepted perception that individuals who are less privileged in society receive less favourable treatment than individuals who are more privileged. We then outline how this is visible in the New Zealand and Australian contexts, to set the scene for the particular issue examined in this study. The second aim of this section is to outline a selection of the literature on a key concept used by-social scientists use to understand intergroup conflict: prejudice. We briefly address stereotyping, as an important connection with prejudice.

This study focuses on the tax system, using tax and welfare fraud for comparative purposes. The study is located in Australia and New Zealand, as they are progressive democracies that are typically associated with egalitarian societies. New Zealand and Australia both have comprehensive welfare systems that provide income supplementation under a range of circumstances. Both countries provide assistance for those who are unemployed, unwell or in other constrained situations, such as being sole parents. While the detail of the-tax systems in each country are different, they both comprehensively tax income from individuals and entities. The New Zealand tax system has a highly effective consumption tax, but few wealth taxes. Unlike New Zealand, the Australian tax system incorporates a comprehensive capital gains tax. Both countries have a broad system of legislated penalties for non-compliance with either the tax or the welfare systems. ${ }^{3}$

\section{Treatment in the Justice System}

Issues relating to the preferential treatment of 'white-collar criminals' when compared to 'blue-collar criminals' have been observed for over 60 years. Sutherland (1949) was among the first to challenge the more lenient treatment given to privileged offenders, suggesting that individuals committing white-collar crime were likely to have greater power, resources and influence: all of which were likely to impact on their treatment in the justice system. From this time, multiple scholars have highlighted the preferential treatment of those committing white-collar crime (Hagan, Nagel and Albonetti, 1980; Weisburd, Wheeler, Waring and Bode, 1991; Hudson, 1993; Nelken, 1997; Croall, 2001; Cook, 2006; Gustafson, 2009; Wacquant, 2009; Reiman and Leighton, 2013).

Various factors contribute to these different outcomes. One of these factors is class. For example, in Sutherland's seminal article of 1940, he suggests that 'respectable, or at least respected, business and professional' people had access to resources and power that facilitated committing financial crime, something that is not available to 'crime in the lower

\footnotetext{
${ }^{3}$ In New Zealand, these penalties are in the Tax Administration Act 1994 and the Social Security Act 1964 for tax offending and welfare offending, respectively. Prosecutions may be taken under the Crimes Act 1961 for both offending categories, which has a higher maximum threshold of penalties. In Australia, the Tax Administration Act 1953 details the general interest charge made for non-payment of tax obligations. This Act also outlines offences and prosecution processes. The Tax Administration legislation in both countries also specifies taxpayers' rights in relation to objections, disputes and reviews. Like New Zealand, tax prosecutions in Australia may also be taken under the Criminal Code Act 1985, which provides for a higher maximum penalty.
} 
class, composed of persons of low socioeconomic status' (Sutherland, 1940:1). While Sutherland's comments date back to nearly 80 years ago, they remain valid in the present day. While our study does not directly address the issue of class, we observe Sutherland's (1940:8) suggestion that the different treatments of blue- and white-collar crime in the justice system could, at least in part, by explained by the following:

persons of the upper socio-economic class are more powerful politically and financially and escape arrest and conviction to a greater extent than persons who lack such power, even when guilty of crimes. Wealthy persons can employ skilled attorneys and in other ways influence the administration of justice in their own favour more effectively than can persons of the lower socio-economic class.

Sutherland's observation has relevance to this study, as it highlights the greater influence and resources that allow for outcomes that are more favourable in the justice system. We also note Brown's (2007) study on race and class in tax policy. Brown highlights the more punitive treatment of lower-income earners in relation to tax audits, where low-income taxpayers are far more likely to be audited than their high-income counterparts' (2007:790).

When one of the offending categories is welfare fraud, the differences between white- and blue-collar offending becomes particularly pronounced. Marston and Walsh report that case law in Australia indicates that 'a sentence of imprisonment is generally considered to be the starting point by the courts in social security fraud cases' (2008:292). This is despite the fact that financial offending undertaken by the wealthy is 'often much greater [in value] than that of common criminals' (Weisburd, Wheeler, Waring and Bode, 1991:7).

The 'type' of offending appears to be a more relevant factor in judging crimes than the harm generated from the crime. Indeed, the social construction of crime is visible in research indicating that individuals view tax offending as less serious than other offences involving similar financial amounts (Cullen, Link and Polanzi, 1982; Australian Institute of Criminology, 1986; McIntosh and Veal, 2001; Orviska and Hudson, 2002; Smith, Button, Johnston and Frimpong, 2011). Moreover, studies that ask respondents to rank crimes in order of seriousness generally report that tax fraud is less serious than other financial crimes (Australian Institute of Criminology, 1986; Evans and Kelley, 2001; Karlinsky, Burton and Blanthorne, 2004; Gupta, 2006). Thus, interpretation of fraudulent behaviour varies across contexts (Cooper, Dacin and Palmer, 2013).

A particular issue is the association made between receiving welfare and welfare fraud. There is evidence throughout multiple societies of prejudice against individuals receiving welfare benefits. The presence of welfare fraud amplifies this prejudice. Again, visibly different narratives exist in the discussions pertaining to the behaviours of those on welfare and the larger group of taxpayers. Illustrative examples from New Zealand, Australia and the United Kingdom show the pejorative language frequently used in association with those receiving welfare assistance: 'scroungers or cheats' (Marston and Walsh, 2008:287); 'wilfully idle, undeserving and lacking in moral fibre' (Cook, 1989:11); 'dole cheats' (Prenzler, 2010:2);' or 'parasites demanding social security while making no contribution to the economy'

\footnotetext{
${ }^{4}$ The term 'dole cheats' is commonly used in Australia to refer to welfare fraudsters.
} 
(Bright, 1978:161). Meanwhile, tax fraud is 'elite crime or crimes of the powerful' (Croall, 2011:11).

The tax discipline is similar to the accounting profession, where for many decades it has been held as a profession that is, as described by Mitchell, Sikka and Willmott, 'beyond reproach' (2001:528). These authors continue to observe how powerful elites police knowledge by producing narratives that discredit alternative voices. The image of tax fraudsters is that they contribute to society; notwithstanding the fact that their non-payment of tax means their financial contributions are absent. ${ }^{5}$ Meanwhile, the image of welfare fraudsters is that they do not contribute and challenge the 'ideals of independence and self-sufficiency' that are venerated in society (Fineman, 2006:135). Fineman (2006) also observes that we perpetuate practices that stigmatise those who are dependent, while ignoring the socio-economic circumstances of people's lives.

\section{Inequity in the Tax and Welfare Systems in New Zealand and Australia}

This sub-section establishes the more punitive treatment of welfare recipients, as compared to tax evaders, in New Zealand and Australia. A dominant assumption is that taxation rules and regulations are transparent, consistently applied and objective. However, evidence suggests that taxation rules may be internally consistent, but when compared across other similar activities, inequities are evident. For example, tax debtors receive more lenient debt repayment obligations then welfare debtors (Marriott, 2014). Tax debtors are more likely to have their repayments reduced or written off if they can establish serious hardship, while welfare debtors are likely to only have their debt written off when all efforts to collect the debt have been exhausted (e.g. the debtor has died and the estate is insolvent) (Marriott, 2014).

Marriott's (2014) study also highlights the different thresholds for serious hardship for welfare debtors and tax debtors. There is no definition for serious hardship in the Social Security Act 1964. The most likely outcome for welfare debtors who experience serious hardship is their repayments may reduce. By way of comparison, serious hardship for tax debtors is outlined in the Tax Administration Act 1994 as including significant financial difficulties that arise where the taxpayer ... would be unable to meet: minimum living expenses estimated according to normal community standards of cost and quality... ' 6 Tax debtors who establish they are experiencing serious hardship may request remission of their debts.

A further example of the different treatment of those who engage in welfare fraud and other financial crimes is visible in a recent change to the Social Security Act 1964. The changes create a situation where the partners of welfare fraudsters become liable for prosecution for the crime committed by their partner. They may also be liable for the debt generated from the offending. The threshold is when the partner 'ought to have known' of the offending, rather than actual knowledge. This change, which was effective from July 2014, results in a

\footnotetext{
${ }^{5}$ See, for example, the work of Croall (2001).

${ }^{6}$ Tax Administration Act 1994, s 177A.
} 
situation where the partners of welfare fraudsters are treated differently from the partners of other financial fraudsters.

Prior research has established different approaches to prosecutions by different government agencies. Recently released data from government agencies shows that the most active prosecution agencies by number of prosecutions were (in order): the New Zealand Police, the Department of Corrections, and the welfare agency - the Ministry of Social Development was third. In the financial year to 2015, the Ministry of Social Development completed 670 prosecutions. Differences are evident when comparing similar government agencies such as the Financial Markets Authority (two prosecutions) or Accident Compensation Corporation (four prosecutions). These two agencies are comparable as they are also involved in financial fraud cases and Accident Compensation Corporation fraud typically relates to over claiming entitlements. A recent media report cites a Crown Law briefing as suggesting that there are different approaches adopted to prosecution depending on whether welfare receipt is part of the crime. ${ }^{7}$

Sentencing outcomes also generate disparities between welfare fraud and tax fraud offences. As the crimes are both financial, they lend themselves to comparison. Prior research has shown that for approximately three times the amount of average welfare offending $(\$ 229,471)$, tax fraudsters have one-third of the chance of receiving a prison sentence when compared to welfare fraudsters (18\%) (Marriott, 2013). The different proportions of investigations and prosecutions suggest a greater willingness by authorities to pursue those on welfare, where criminal activity is present.

Similar patterns are visible in Australia with the different treatments of welfare and tax fraudsters. As with New Zealand, only a small percentage of tax lodgements result in disputes, objections and reviews; relatively small proportions receive referral for prosecution; and conviction rates from prosecutions are high. Investigations of welfare recipients totalled 3.5 million reviews in 2009-10 (Lindley, Jorna and Smith, 2010:3). Prosecutions in Australia as a proportion of customers are typically around 0.05 per cent (Marriott, 2013). Like New Zealand, conviction rates from prosecutions are high at 99 per cent. However, the average saving per prosecuted offence is not high. Savings per prosecution range between A $\$ 29,000$ A $\$ 52,000$, but the average saving per adjustment after investigation is between $A \$ 165$ and A $\$ 199$ (Lindley, Jorna and Smith, 2010). This indicates that a large number of reviews and investigations occur in relation to very small amounts of incorrect claims.

While the information available in the two jurisdictions is not identical, both countries clearly show different treatments of welfare and tax fraudsters in the justice system. There are more investigations and prosecutions of welfare fraud than tax fraud in both countries and prosecutions commence at a lower level of offending for welfare fraud. The different approaches to investigations, prosecutions and sentencing of welfare crimes suggests a greater willingness to both pursue and to punish offending by those receiving welfare benefits.

\footnotetext{
7 Reported in the Dominion Post, 17 February 2017. Available at: http://www.pressreader.com/newzealand/the-dominion-post/20170210/282535838114056, retrieved 4 March 2017.
} 
The approach to investigation and prosecution of tax fraud may affect its perception. Tax crime is of significantly greater economic importance than welfare crime. However, the differences in treatment of the two crimes suggests that welfare fraud is the more serious offence and likely to generate considerable damage to the social fabric. Lehman and Okcabol observe this phenomenon when noting that crime management, including underreporting of some statistics, comprises 'part of a complicated political process by re-constructing meaning and imbued with social practices' (2005:615).

The approach adopted to the investigation and prosecution of tax fraud leads to underreporting of this offence, through the process of negotiated settlements. This situation arises as non-compliant taxpayers may negotiate outcomes with the tax authority and thereby avoid prosecution. This option is not available to welfare fraudsters. While New Zealand and Australia are typically regarded as largely honest jurisdictions, ${ }^{8}$ there are clearly more than a handful of tax fraud cases in most years, which is the impression given by the few tax fraud cases that can be witnessed in the criminal courts. By way of contrast, the greater number of investigations and prosecutions, together with harsher sentences, provides support to the generally accepted belief that welfare fraud is a more serious crime than tax fraud.

The circular feature of these crimes is similar to that observed by Dillard in relation to accounting, whereby in the absence of an intervention, 'distortions are interpreted as objective representations of "real" phenomena' (1991:9). The common link with the tax and welfare fraud dynamic that is the focus of this article, is that the societal framing of welfare fraud as the more serious offence, minimises the opportunity for critique that would allow the dominant cycle to be broken. To paraphrase Dillard where accounting is replaced with tax, if the images of existence are not directed toward alternative ideological mirrors and the distorted, yet differently distorted, "realities" considered, then [tax] will continue to reinforce and reify the social system from which it emanated' (1991:9).

\section{Prejudice}

This study investigates prejudice as it 'can usefully be regarded as the outcome of conflicting group goals' (Brown, 1995:203). In the groups we examine in this study, the group that we expect to see as the oppressed group is the group of welfare fraudsters. Inevitably, there are insufficient resources to provide sufficient financial support to allow everyone in society to have their desired standard of living. Therefore, when people take more from the system for themselves, all the others in the group suffer. Tax fraudsters achieve the same outcome, but without application of similar negative attitudes.

Duckitt (1992) observes the range of concepts used by-social scientists use to assist with explaining inter-group conflicts. Among these are tolerance, ethnocentrism, stereotype, racism, discrimination and prejudice. Prejudice is the focus on the current study as it has been 'accorded primacy' among these factors (Duckitt, 1992:7). However, the commonalities and

\footnotetext{
${ }^{8}$ For example, see Transparency International's Corruption Perception Index, where New Zealand and Australia both rank highly in terms of levels of public sector corruption.
} 
overlaps between these concepts are recognised, and all of these concepts are likely to affect the results reported herein to a greater or lesser extent.

Typically, there are four generally agreed factors involved in the definition of prejudice:

1. It is an inter-group phenomenon;

2. It is negative;

3. It is undesirable; and,

4. It is an attitude (Duckitt (1992), citing Ashmore 1970:9). ${ }^{9}$

Attitudes are generally agreed to be a 'latent or underlying variable that is assumed to guide or influence behavior' (Fishbein and Ajzen, 1975). Attitudes are learned tendencies that inform responses to an object. Typically, these exist on a spectrum of favourable to unfavourable. Beliefs inform the attitude held by the individual in relation to the object, with stronger or weaker beliefs reflected in the extent of prejudice held towards the object. Fishbein and Ajzen (1975) suggest that intentions are a special case of beliefs, where the strength of the intention determines the probability that the person will perform a particular behaviour. For some time, social psychology research has united in accepting that attitudes do not appear to have a strong impact on behaviour (Terry, Hogg and Blackwood, 2001).

Intergroup relations have been the focus of many discussions on prejudice. The fundamental principle is that people favour their own groups over others (Pratto, Sidanius and Levin, 2006). Prejudice towards out-groups is generated with the practice that large numbers of people in any segment of society will broadly agree in their negative stereotypes of any given outgroup and will behave in a similar way towards them' (Brown, 1995:10). Intergroup conflicts can take the form of competition for resources, domination of one group above another, or disparities in size or status (Brown, 1995).

There are numerous examples that confirm the correlation between intergroup domination and the belief of the inferiority of the minority or oppressed group (Duckitt, 1992:101). One of the roles played by the minority group in ensuring the maintenance of the extant hierarchy is in taking the role of the scapegoat for activities disapproved of by the dominant group. Having a scapegoat facilitates cohesion within the dominant group, particularly when the minority group is already a group that is resented (Duckitt, 1992). This is particularly relevant for the welfare and tax fraudthe topic that is under examination inthe topic of this studystudy, which is welfare and tax fraudsters. Welfare fraudsters are a subset of people who are receiving welfare benefits. Society does not view either welfare recipients or fraudsters favourably. However, views of tax fraudsters are that they are clever or entrepreneurial. Welfare fraudsters meet the criteria of a minority or oppressed group, particularly as they are often not well organised, usually have few resources, and typically have little in the way of political influence, power or support. In contrast, tax fraudsters often retain power, influence and networks, notwithstanding criminal activity.

\footnotetext{
${ }^{9}$ Refer to Duckitt (1992:10) for more detail on definitions of prejudice.
} 
Duckitt (2001) reports that prejudice tends to be generalised over targets, that is, individuals who hold less favourable attitudes to one minority or oppressed group are also likely to hold less favourable attitudes to other minority or oppressed groups. There are multiple reasons why individuals may hold unfavourable views about welfare fraud. For example, the media reports on both welfare and tax fraud prosecutions. However, as welfare fraud is more likely to be prosecuted than tax fraud for a similar quantum of offending, it appears more frequently in the media. ${ }^{10}$ Thus, individuals may readily overestimate the presence of welfare fraud in society when compared to tax fraud. This phenomenon, referred to as illusory correlation in the social psychology literature, provides for individuals to assume high rates of welfare fraud among welfare recipients, as compared to tax fraud among taxpayers, due to overestimates of the frequency of welfare fraud. Thus, as noted by Hamilton and Gifford, different perceptions of groups may result solely from 'cognitive mechanisms involved in processing information about stimulus events that differ in their frequencies of cooccurrence' (2000:161).

While the study of intergroup conflicts focuses on group ideals, the focus can also be on the influence of the group on individual attitudes. In many cases, stereotyped perspectives on out-groups act to reinforce attitudes. Brown describes stereotyping as 'a phenomenon at the heart of the study of prejudice' (1995:82) and 'a cognitive association of a social category with certain characteristics' (1995:90). More simply, they are described by Locke and Johnston (2001:108) as 'mental representations of social groups and their members which contain enough detail to allow us to know what group members are like without ever meeting them'. As well as including the likely traits of that group, these mental representations will also generate expectations of how the group members will behave. Stereotypes may result from cultural influences, socio-economic differences, or from cognitive bias that results in illusory correlations between minority or oppressed groups and infrequently occurring attributes (Brown, 1995).

Part of the wider problem in relation to attitudes towards those who engage in tax fraud and those who engage in welfare fraud is the reinforcement of knowledge relating to the two crimes. To the extent that harsher punishments are noticeable for welfare fraud, the act becomes conceptually a more serious crime. This phenomenon is raised by Mitchell, Sikka and Willmott, who observe the need to foster an awareness of how forms of power, including legal processes, constrain as well as enable the dissemination of knowledge' (2001:527).

The link between stereotypes and prejudice is that prejudice 'captures the affective nature of the response to members of different social groups' that may result from stereotypes (Locke and Johnston, 2001:108). Different people will hold dissimilar levels of prejudice towards certain groups, which affects how they evaluate that group. Those who are more prejudiced will use negative information about a group to judge that group and reinforce negative attitudes (Locke and Johnston, 2001).

\footnotetext{
${ }^{10}$ A search on one of the primary New Zealand news websites for 'tax evasion' returns 2,100 results and for 'benefit fraud' returns 7,590 results (search undertaken 26 February 2017 on website www.stuff.co.nz).
} 
Research outputs typically agree that stereotyping influences perceptions and judgements of people or events. For example, Darley and Gross (2000) report that individuals assessed children to be of higher or lower academic ability when told the child was from a high- or low-socioeconomic background, respectively. Darley and Gross (2000) suggest that this stereotype information does not create certainties about individuals, but rather allows hypotheses to be formed about the stereotyped individual, which are then 'tested' in a biased fashion, allowing their false confirmation.

Group affiliations may affect stereotypes. These group affiliations can result in people being more likely to agree with favourable stereotypes of their own groups and less likely to agree with favourable stereotypes of other groups: another example of illusory correlations. Thus, a form of positive social identity develops with one's own group(s), which, if threatened, may result in intergroup conflict. Social identity theory suggests that a desire for an in-group to maintain a positive social identity motivates attitudes towards that group (Terry, Hogg and Blackwood, 2001). Research has shown that even when the basis for a group membership is random, individuals favour their in-group, leading to the conclusion that where a group is self-inclusive, this is sufficient condition to generate hostility to other out-groups (Terry, Hogg and Blackwood, 2001).

\section{TAX AND INEQUITY}

In many ways, critical tax research is no different from critical accounting research. In a recent article commemorating 25 years of a critical accounting journal, Morales and Sponem, raise a number of objectives of the critical accounting approach including: it must question the power of any group to determine what is appropriate; it engages with theory to determine conditions to assist with emancipation; it proposes reforms and exposes dysfunctions; and it can 'convey the social, political and human complexities of accounting institutions' (Morales and Sponem (2017) citing Cooper (2014)). Critical tax research has these same objectives.

This section provides a brief illustration of the tax research that has considered inequity. In its most traditional use in taxation, equity is one of a small number of 'principles' typically considered desirable in tax policy. Different ways of looking at equity are used in the tax literature, e.g., horizontal and vertical, or progressive and regressive. The common feature is some component of 'equal' - notwithstanding that 'equal' is achievable by treating all the same, or all differently, depending on the circumstances.

Research on inequity often focuses on economic inequity, emphasising the differences in returns to capital and labour (for example, Piketty (2014)), and the subsequent relationship between inequity and increasing inequality. While this is important, this section highlights the additional contribution that critical tax research has made in extending the issue into the social and legislative domain. What is common in the majority of the literature is that it focuses on the tax system and the ways in which the regime of tax legislation and its interpretation can result in inequitable outcomes. This study adopts a different focus and instead it examines how tax, in general, is privileged. This may be because tax funds economic and social activity, and thus has a worthy objective. Meanwhile, welfare is an 
expenditure item, with recipients demonised for the lack of self-reliance that is the ideal when viewed through a neo-liberal lens. Work by Boden, Childs and Wild (1995) explores this further, highlighting the 'anti-welfare notions' that result from the concept of economic citizenship and the expectation of self-reliance. Brown provides further evidence in her observation that in America "“welfare recipients" equal lazy blacks, who would rather receive money from the government than work' (2007:794). This is notwithstanding the close connection of the tax and welfare schemes in relation to social objectives.

While the traditional concepts of equity within tax have been widely critiqued, inequity has not faced the same level of inquisition. Infanti captures this idea when he writes that tax equity is 'solely concerned with the fair treatment of individuals who either have the same or different incomes' (Infanti, 2008:1195). Infanti continues to observe that this represents a normative choice 'to consider economic differences - and only economic differences - in determining the fairness of a tax...' (2008:1195). Infanti's express aim is to raise consciousness of the taken for granted nature of fairness in tax research and extend thinking to 'embrace not only fairness to the privileged among us, but to the oppressed as well' (2008:1197).

Knauer (2014) adopts a similar stance, observing that tax policy adopts terms of neutral outcomes, while simultaneously disregarding characteristics of taxpayers that may lead to outcomes that are not neutral, such as gender, ethnic group or socioeconomic position. Instead, tax policy formation uses large-scale models that group taxpayers into income groups or expenditure categories. As Knauer (2014:210) writes, 'the fiction of taxpayer neutrality is a constituent feature of optimal tax theory, which seeks to maximize social welfare by identifying the optimal tax base'.

Similar views are visible in the field of critical tax research. Critical tax scholars have made strong contributions to address the issues raised by Infanti and Knauer raise. While some of these are more traditional tax topics, such as the extent to which fairness affects tax burdens (for example, Farrar, 2011) or tax reform (Knauer, 2014), a range of interdisciplinary work addressing inequity is also evident. Examples include gender equity and tax (see, for example, Blumberg, 1971; Livingston, 2002; and Grown and Valodia, 2010); tax discrimination and ethnicity (see, for example, Moran and Whitford, 1996, and Brown, 2007); the role of tax administration and administrators (Tuck, 2010); how the tax system is used to influence the choices of women (Mumford, 2009); or inequities that result for samesex couples from the tax regime (Knauer, 1998), among others. A further topic that has attracted discussion is a more fundamental consideration of tax equity: who pays tax. See Infanti (2007) for a thorough discussion of this field or Gracia and Oats (2010) who discuss the related topic of tax avoidance and tax evasion. All of these examples address components of inequity relating to, or resulting from, taxation. Some directly address inequity by exploring the inequitable outcomes for different groups from the tax rules, while others show how the tax rules privilege the wealthy.

Infanti observes that 'the problem is not that "mainstream" and critical tax scholars are talking past each other, but that critical tax scholars attempt to frame their discussions in tax equity terms at all' (2008:1195). Infanti's argument is that tax equity focuses on the 
economic differences in determining tax fairness. Infanti refers to the insidious homogenization of the population' that results in tax equity performing a 'sanitizing and a screening function' (2008:1196) as it eliminates difference that takes other forms, such as gender or ethnicity.

This idea is further developed by Boden et al (2010:541) further develop this idea in observing, who observe the 'othering' of taxation, which may be the result of professional preference to maintain tax as a technical discipline to keep prying eyes from closely examining the hidden power plays at work'. Boden et al further note that the field of tax research is typically the domain of positivism typically dominates tax research, whether this takes the form of black-letter law interpretations or the economic cost-benefit approach to tax policy (2010). Boden et al combine these two issues - the marginalisation of tax research and the traditional approaches to tax research - to suggest the outcome is 'the absence of an understanding of the operation of power in a social contract that touches the lives of all' (2010: 541).

Boden et al's claim about the dominance of positive research in the tax discipline is visible in all components of the literature: the publication outlets, the topics covered and the methods used. Moreover, this positive influence has been visible in early literature examining the behaviour of taxpayers when these taxpayers believed the tax system was inequitable. Falkinger (1988:388) captures the general finding of these studies: 'tax evasion is a means to adjust the corresponding terms of trade with government if they are perceived to be unfair' (1988:388). Many of these early tax studies were experimental (Spicer and Lundstedt, 1976; Spicer and Becker, 1980), theoretical (Cowell, 1985; Forest and Sheffrin, 2002) or empirical (Wallschutzsky, 1988) and typically reported that perceptions of inequity were a factor in taxpayers' decisions to evade their tax obligations. In time, critical research supplemented these economically grounded studies, which reaches across a broader construct of inequity than that visible in the field of public finance.

The tax community's ability to engage with technically complex material is well--established. However, Boden et al (2010:541) note that in the absence of a critical social science perspective 'this technical approach to tax fails to penetrate structural rules and their application'. Furthermore, it minimises the opportunity we have to highlight the power imbalances in society that are generated and maintained within the broader tax discipline. Thus, one of the aims of this study is to highlight the lack of equivalence in the treatment of welfare and tax offenders, where those in the group of tax offenders are more likely to represent those with the most power and influence in society. While the breadth and depth of critical tax research has undoubtedly expanded over recent decades, there is still much work needed to highlight the bias that, as captured by Knauer, 'is often obscured by the misplaced belief in the inherent neutrality of taxation' (2012:230).

\section{SOCIAL DOMINANCE THEORY}

The foundation of social dominance theory is the belief that all societies are systems of group-based social hierarchies (Sidanius and Pratto, 1999). Dominant groups are 
characterised by 'possession of a disproportionately large share of positive social value, or all those materials and symbolic things for which people strive' (Sidanius and Pratto, 1999:31), such as power, authority, or status. Those in subordinate groups possess a large share of negative social value, such as little power and authority, few possessions and low social status. A fundamental assumption of social dominance theory is that groups engage in behaviours to facilitate the endurance of extant hierarchies.

Sidanius et al (2004) propose that social institutions, as well as powerful individuals, disproportionately allocate desirable and undesirable goods in society, with the result that those who are less powerful receive greater amounts of undesirable goods, such as punishments. Social dominance theory proposes that an individual's measure of social dominance orientation drives attitudes towards out-groups. Social dominance orientation is 'the basic desire to have one's own primary in-group (however defined) be considered better than, superior to, and dominant over relevant out-groups' (Sidanius et al, 2001:153). The general orientation toward group-based social hierarchy is social dominance orientation (SDO) (Sidanius and Pratto, 1999:39). This study uses the 16-question SDO measurement scale (Sidanius and Pratto, 1999), as provided in Appendix I.

People who are more social-dominance oriented will prefer hierarchy-enhancing policies that allow for group-based dominance, such as those in the criminal justice system that award harsher punishments to those in subordinate social groups. Conversely, those lower on social dominance orientation are more likely to: reflect preferences for 'egalitarianism and altruistic social concern' (Sibley, Robertson and Kirkwood, 2005:172); show preference for policies that are hierarchy-attenuating (Pratto et al, 1994); and are more likely to favour equality in the justice system. Thus, the SDO criteria may be divided into those measures that score high on dominance (questions 2, 4, 6, 8, 10, 12, 14 and 15) and those that score high on egalitarianism (questions 1, 3, 5, 7, 9, 11, 13 and 16).

There are multiple reasons for adopting SDO in this study. Social dominance theory is a powerful predictor of generalised prejudice (Duckitt et al, 2002; Duckitt and Sibley, 2010) and intergroup phenomena (Duckitt, 2001; Ho et al, 2012). In addition, SDO is an effective predictor of attitudes where the foundation of intergroup relations is inequality and where intergroup relations are characterised by high levels of threat to group values and security (Sibley, Robertson and Kirkwood, 2005). ${ }^{11}$ SDO is 'highly reliable' (Duckitt et al, 2002:76) and 'highly stable over time' (Sidanius and Pratto, 1999:68). Ho et al (2012:584) describe SDO as 'one of the most versatile and useful constructs for understanding socio-political ideologies, the psychology of prejudice, and intergroup behaviour'. Furthermore, studies have shown a negative correlation between social dominance orientation and traits such as empathy, tolerance and altruism (Pratto et al, 1994).

Of particular relevance to this study is the suggestion by Sidanius and Pratto (1999) that the criminal justice system is a social institution that systematically reproduces group-based

\footnotetext{
${ }^{11}$ For example, Sibley, Robertson and Kirkwood (2005) have used SDO to predict attitudes towards MāoriPakeha relations in New Zealand.
} 
hierarchy. These hierarchies are visible in the treatment of minority groups in the criminal justice system, as well as in the different treatments of tax and welfare fraudsters.

\section{RESEARCH QUESTIONS, METHODOLOGY AND CHARACTERISTICS OF RESPONDENTS}

The major aim of this study is to highlight, challenge and explain the inequity resulting from the treatments of different societal groups. This section commences with the research questions and research design adopted to address these aims. The section also outlines the characteristics of the survey respondents.

\section{Research Questions}

The study focuses on prejudiced attitudes towards different types of people. As noted in the literature in section three, one of the aims of critical accounting (and tax) research is to question and challenge power relations and situations that result from power relations. Given the anti-welfare notions highlighted in section three, we expect attitudes towards those who are engaging in welfare fraud to be more punitive than towards those who engage in tax fraud. This expectation results from the perception of a generally negative attitude towards those who are in receipt of welfare, notwithstanding any welfare fraud. Therefore, we expect exacerbation of this attitude when fraudulent activity is present. This leads to the first research question in our study.

1. To what extent are attitudes towards welfare fraud more negative than attitudes towards tax fraud?

By asking this question in the New Zealand and Australian environments, which are often believed to be relatively tolerant societies, we provide further support for the extant literature that illustrates the presence of prejudice against those who are marginalised in society. We subsequently set out to examine the influence of prejudice on attitudes and for this we use social dominance theory. Following social dominance theory, we expect that individuals will identify more positively with their own group. Thus, our second research question is:

2. To what extent do individuals believe that their own group is more or less likely to commit tax fraud or welfare fraud?

This potential presence of inter-group stereotypes and prejudice against out-groups resulted in the use of social dominance theory for analytical purposes in this study. The theory allows us to highlight where equal relations are preferred, or whether an individual prefers their own group to dominate. In asking this question through the frame of social dominance, we examine whether prejudice within hierarchies exists that will limit potential social change.

\section{Research Design}

We collect data via an online survey. A representative sample of the New Zealand and Australian population received the electronically distributed survey. An independent research company holding a database comprised of individuals belonging to a retail rewards programme in each country distributed the email. The database held approximately half of 
the population in both New Zealand and Australia. While the database holds a large proportion of the population, as it is a retail rewards scheme, higher socio-economic individuals have greater representation. However, this limitation does not restrict the targeting of a representative sample of the New Zealand and Australian populations based on the most recent census data.

We excluded those aged under the age of 18 due to their limited engagement with the welfare or tax systems. Individuals received rewards in the form of retail 'points' from the retail reward scheme for participating in the survey. ${ }^{12}$ This ensured anonymity of respondents from the researchers. The study received Human Ethics approval from the university of the first author.

The database holder sent a large number of emails $(15,000)$. The experiment was available for people to complete until the requisite number of completed surveys (1,500 in Australia and 1,500 in New Zealand) was received, which was approximately three days. At this time, the survey closed.

All respondents were required to complete the survey in order to receive their retail reward points, although for some questions (income, age, etc.), people could respond 'Prefer not to say'. We coded these as missing. When we required the subjects to have complete responses for all the demographic variables, we were left with 2,527 respondents, 1,266 (50.1\%) from New Zealand, and 1,261 (49.9\%) from Australia. We then considered the characteristics of the study participants separately by New Zealand and Australian respondents.

\section{Country Selection}

New Zealand and Australia are frequently utilised in cross-country studies, as they lend themselves to effective comparative studies. They are both successful southern-hemisphere Commonwealth countries with similar demographic profiles, social policy objectives and British colonial heritage (Marriott, 2010). The countries have parliamentary governments, are both OECD member countries, are geographically close and have close trade relationships.

This study does not compare between the two countries and instead uses the two countries together to examine for different responses to the same events. We use Australia and New Zealand, as they are sufficiently similar from an economic, social and legal perspective. For example, McLean (2003:14) claims that these two have more in common with one another than either has with any other country on the planet ... they are probably simply more alike than any other two separate nations' (2003:14); and suggests that:

There are strong personal and social affinities between the two peoples and close links by modern transport; both are liberal, moderate democracies, fortunate and successful states with a far-reaching network of co-operation between them; there are no divisive legacies of bitterness or wars: there is nothing of a racial, religious, ethical or linguistic character to provide any pretext for apart-ness.

\footnotetext{
${ }^{12}$ Upon receipt of the email requesting participation, individuals received a link to the experiment. Completion of the experiment provided individuals with a code that allowed collection of the reward points.
} 


\section{Characteristics of Survey Respondents}

The survey collected a range of demographic variables. This section discusses those that are most relevant to the analysis, together with the traditional variables of gender and age. We do not include tables outlining the variables, in the interests of space. However, details of respondents are available from the authors on request. The gender responses were $48 \% / 52 \%$ male/female in New Zealand and $46 \% / 54 \%$ in Australia. We received a good range of age responses, noting that we only requested responses from those aged over 18 . The survey has large numbers of European responses - New Zealand European in New Zealand and Australian European in Australia. As compared to census profiles, New Zealand Māori and Pasifika are under-represented in New Zealand. Asians have higher representation in Australia at $13.3 \%$ (approximately $7 \%$ of the Australian population identify with at least one Asian ethnicity) and lower representation in New Zealand at $4.6 \%$ (approximately $12 \%$ of the New Zealand population identify with at least one Asian ethnicity).

We grouped respondents into three professional groups. Nearly half (48.1\%) of Australian respondents have classified themselves as unskilled, as compared to $30.4 \%$ of New Zealanders. In the Manager/Professional category, New Zealand has greater representation at $38.6 \%$, compared to $24.3 \%$ for Australia. This aligns with other variables, which show that Australian respondents are younger and more receive welfare benefits than New Zealand respondents.

In both Australia and New Zealand, the main source of income is from wages and salaries: $58 \%$ in Australia and $67 \%$ in New Zealand. In Australia, 16\% of respondents reported receiving a pension while $17 \%$ of New Zealand respondents reported the same. New Zealand respondents reported that $12 \%$ per cent were self-employed, as compared to seven per cent of Australians. Only small proportions of people had no source of income, or income from capital, in both countries. We have a considerably higher proportion of people reporting as being on a benefit in Australia at $14.5 \%$ as compared to New Zealand at 3\%. We separate old-age pensions and other welfare benefits in this grouping. The proportion of the working age population (18-64 years of age) in receipt of welfare benefit is $18 \%$ in Australia (Australian Council of Social Services 2014) and 11\% in New Zealand (Ministry of Social Development 2014). Therefore, both countries are under-represented in the survey by individuals in receipt of welfare benefits.

\section{Social Dominance Orientation Scale}

The survey had 80 questions, but we do not include all the questions in this article. We positioned the SDO questions at the end of the study, after all the questions on perceptions of tax or welfare had been finished. We told respondents: 'we would now like to ask your views on a range of topics relating to groups within society. Please click on the response that best reflects your view'. The questions outlined in Appendix I followed. 
The SDO scale is a widely used social psychological scale. It consists of 16 items, each scored from 1 (strongly disagree) to 7 (strongly agree). ${ }^{13}$ We divide the scale into two 8 -item sub-domains (Dominance and Egalitarianism). ${ }^{14}$

We calculate scores by taking the mean of the items for that score, after appropriate reverse coding for items asking 'negatively'. The two-factor solution for the SDO in our sample gave the same result - splitting the items into the same ones defined for Dominance and Egalitarianism - as reported in the literature. In our sample, the Cronbach's alpha for all 16 items was 0.890 (95\% CI: 0.883, 0.896), for the 8-item Egalitarianism score, Cronbach's alpha was $0.871(0.863,0.878)$, and for the 8-item Dominance score, alpha $=0.873(0.865$, $0.880)$.

Table 2 outlines the means and standard deviations for our sample.

\section{(Insert Table 2 About Here)}

\section{FINDINGS}

In order to address the question of whether people are likely to believe their own in-group is more or less likely to engage in a particular crime, we examine the likelihood that the respondent thought a 'type' of person would be more or less likely to evade tax or engage in welfare fraud. We pose two scenario-based questions to respondents as follows:

(1) Tax Fraud Scenario. You read in the newspaper that someone has been caught evading tax. If you knew the following about them, do you think it is more or less likely that the person is guilty?

(2) Welfare Fraud Scenario. You read in the newspaper that someone has been caught committing welfare fraud. If you knew the following about them, do you think it is more or less likely that the person is guilty?

For each of the scenarios, we provided seven options:

1. The person did not have a job

2. The person owns their own home

3. The person is of Māori ethnicity

4. The person is a businessman

5. The person receives a welfare benefit

6. The person is an immigrant from the United Kingdom

7. The person is an immigrant from Tonga

We collected responses on a 7-point Likert scale from 1 (more likely) to 7 (less likely). We did not give any additional anchors with the exception of a mid-point anchor at 4 (undecided).

\footnotetext{
${ }^{13}$ For further detail, see Sidanius and Pratto (2001).

${ }^{14}$ For further detail, see Ho et al (2012).
} 
We selected these options due to expected stereotypes of particular types of people. The Māori group is included as Māori are the indigenous people of New Zealand and comprise approximately $15 \%$ of the population. Historically they have been the target of negative stereotypes (e.g. 'lazy, slovenly and inefficient and not able to cope with the strict time demands of the capitalist world'). ${ }^{15}$ As the indigenous Aboriginal population in Australia is around two per cent, we did not set out to investigate Aboriginal responses, as we believed it was unlikely that we would get sufficient responses to engage in meaningful analysis.

We used repeated measures analysis of variance to test whether the average 'likelihood of being guilty' differed by the seven different 'types' of people outlined above; whether there were differences by scenario; and whether the differences by person differed by scenario (the interaction effect). We use Bonferroni post-hoc tests to determine which 'types' of people differed from each other. Table 3 outlines the results of the overall analysis, which shows a significant difference by scenario, by person and a significant interaction.

\section{(Insert Table 3 About Here)}

The results of the analysis of both scenarios were difficult to interpret, therefore we analysed each scenario separately. The one-way ANOVA used is equivalent to a two-sample t-test. This ean be usedis suitable for even very small sample sizes $(<15$, for example). As our sample sizes are at least 50 in every group, there is no problem with lack of power. The other assumption of the t-test is that the data are normally distributed. To deal with this possibility, we conducted non-parametric tests (Wilcoxon tests, the non-parametric equivalent to the ttest). The results remain the same. Table 4 reports the means by scenario and by person.

\section{(Insert Table 4 About Here)}

Table 4 shows that by ranking, respondents felt those least likely to engage in tax fraud were those who did not have a job, while the person most likely to engage in tax fraud was the businessman. These are expected responses, as it is reasonable to assume that someone who did not have a job was not in a position to evade tax (as they have no income). In a similar way, a businessman has the greatest opportunity to engage in tax fraud.

For welfare fraud, the person viewed as most likely to engage in welfare fraud is the person in receipt of welfare. The person viewed as least likely to engage in welfare fraud is the immigrant from the United Kingdom. As those who are eligible for welfare are those most likely to be in a position to take advantage of the scheme, these are also expected responses. Immigrants from the United Kingdom are less likely to be eligible for welfare payments in either New Zealand or Australia, so it is a valid assumption that they may be the group least likely to be able to engage in welfare fraud.

In order to examine the influence of in- and out-groups in this study, we investigated whether the respondent's choice differed by whether they were a similar or a dissimilar person. For both scenarios, we provided the Māori ethnicity option. Table 5 outlines the mean responses to these questions by Māori and non-Māori.

\footnotetext{
15 Te Ara The Encyclopedia of New Zealand. Story: European ideas about Māori. Retrieved from: http://www.teara.govt.nz/en/european-ideas-about-maori/page-6, 18 February 2017.
} 


\section{(Insert Table 5 About Here)}

As can be seen in Table 5, when we asked Māori about a Māori person, they give a higher value than when we asked non-Māori about a Māori person. That is, Māori respondents believe that Māori are less likely to engage in tax and welfare fraud than non-Māori respondents. The mean differences are statistically significant for tax fraud and almost significant for welfare fraud.

The next group we examined was the businessman. We classified the in-group as men, who had identified in the manager/professional occupation grouping. Table 6 outlines these results.

\section{(Insert Table 6 About Here)}

For both scenarios, businessmen give people like them higher scores, that is, they believe they are less likely to engage in either crime, than non-businessmen. The difference in means is larger for tax fraud than for welfare fraud. This shows businessman respondents believe that they are less likely to commit these crimes than other people think they are.

The third group we examined was the group of respondents who were in receipt of welfare benefits. We identified these groups from those who responded that their sole source of income was from benefits. Table 7 reports these results.

\section{(Insert Table 7 About Here)}

As with the other two groups, the in-group (i.e. those receiving welfare benefits) scored the person on a benefit more highly than respondents who had some other source of income did. That is, they perceived that the person receiving welfare benefits was less likely to be guilty than other respondents.

The next question we address is how does social dominance orientation affect this relationship between in- and out-groups, and their responses about the likelihood of who will engage in the financial fraud. To examine this, we fit General Linear Models to model the relationship between Group (Māori, Businessman and Welfare Recipient), Social Dominance Orientation (split into its two constituents Dominance and Egalitarianism), and the outcome variable (the likelihood of being guilty of tax or welfare fraud). For each model, the results gave p-values for Group and for whichever Social Dominance Orientation variable used, and parameter estimates, which gave the direction of the relationship. Table 8 outlines these results.

\section{(Insert Table 8 About Here)}

For each predictor (Dominance, Egalitarianism and Māori) and for each model (Tax Fraud or Welfare Fraud), the table gives the estimated coefficient, and its p-value. For Dominance and Egalitarianism, where the coefficient is positive, this means that as Dominance or Egalitarianism increases, the score increases, that is, the respondent believes the person is less likely to be guilty. Where the coefficient is negative, higher values of Dominance or Egalitarianism mean lower scores, that is, the person is more likely to be guilty. For the Māori variable, a negative coefficient means the score is lower for non-Māori than for Māori. 
For Māori, Dominance and Egalitarianism were more important statistically than was the ethnicity of the respondent. The ethnicity was not significant, although there was always a trend towards statistical significance. This may have been due to the small sample size. The direction was always the same: Māori gave higher scores than non-Māori (negative coefficient, therefore less likely to be guilty). The coefficients of Dominance were negative, so that as a person's Dominance score increased, they would consider a Māori person more likely to be guilty. The reverse was true for Egalitarianism, that is, the more egalitarian the respondent was, the higher the score, i.e., the Māori person was less likely to be guilty.

Table 9 outlines the models for the businessmen. In these examples, non-Businessmen gave a lower score on average, that is, they perceived the businessmen as more likely to be guilty, than the businessmen did. This result was statistically significant for both scenarios. The coefficients for Dominance were positive for the tax fraud example and negative for the welfare fraud example. Therefore, for tax fraud, respondents with higher Dominance scores gave higher scores for tax fraud, that is, businessmen were less likely to be guilty. For the welfare fraud scenario, respondents with higher scores for Dominance gave a lower score, indicating that businessmen were more likely to be guilty. This finding is unexpected. However, to the extent that respondents believe that businessmen can structure their financial affairs more effectively than traditional employees, there may be a perception that they are receiving state benefits (such as working tax credits) if their incomes are artificially low. The media has reported examples of such behaviour in recent times. For Egalitarianism, the effect was similar for both scenarios - higher egalitarianism was associated with a lower score, that is, increased likelihood of being guilty.

\section{(Insert Table 9 About Here)}

Table 10 outlines Welfare recipients, our final example. There was no association between Dominance or Egalitarianism, and the likelihood of being guilty of welfare fraud. However, if the respondent was a welfare recipient, they scored the likelihood of guilt lower (i.e. more likely) than if the respondent was not a welfare recipient. There was a strong statistical relationship between Dominance (but not Egalitarianism) and the likelihood of being guilty of tax fraud. Again, higher values of Dominance were associated with lower scores (more likely to be guilty) and higher values of Egalitarianism were associated with higher scores (less likely to be guilty). In all situations, welfare recipients scored themselves higher (i.e. less likely to commit the crime) than non-welfare recipients scored them. For welfare recipients, all that matters is the in-group and out-group. Unlike the other two groups, dominance and egalitarianism is not important.

\section{(Insert Table 10 About Here) \\ DISCUSSION}

Cooper, Dacin and Palmer observe that fraud is not 'personal nor universal' and instead is 'situated in specific social and historical contexts' (2013:445). This was evident in the prejudice views held by our survey respondents. These views align with expected stereotypes: businessmen evade tax or people receiving welfare benefits engage in welfare 
fraud. When we examine views on the likelihood of 'who' will engage in tax or welfare fraud, we find different stereotypes among different groups.

The literature on prejudice, together with social dominance theory, suggests that affiliation with a group generates a more positive stereotype of that group. This is evident in the findings reported in this study. Our more detailed analysis of in- and out-groups (Māori and non-Māori, businessmen and non-businessmen, and recipients of welfare and non-recipients of welfare) showed a strong presence of preference for one's own group. In all cases, the ingroup believed that their own group was less likely to commit the crime - regardless of whether the crime was welfare or tax fraud - indicating the presence of the positive social identity suggested by social dominance theory.

We find evidence of prejudice towards Māori people among the respondents who scored high on SDO dominance measures, whereby these respondents considered that a person of Māori ethnicity was more likely to be guilty of tax or welfare fraud. The opposite was visible among respondents who scored high on SDO egalitarianism. However, we find that for those who scored highly on SDO dominance measures, they are more likely to think favourably about how businessmen will behave in relation to tax fraud (i.e. that they are less likely to engage in tax fraud), but more likely to engage in welfare fraud. We find a similar result with those who scored highly on SDO egalitarianism measures, whereby higher egalitarianism was associated with increased likelihood of committing either crime. This response for businessmen aligns with the inherent prejudice that is prevalent with welfare fraud. Those who score highly on SDO dominance measures are those who have agreed with statements suggesting that some groups of people are more worthy than others, that some groups of people should stay 'in their place', and that it is a good thing that some groups are at the top and others are at the bottom (among other questions). Thus, dominance is associated with superiority of certain groups and businessmen are likely to be a group that is more desirable and superior than other groups.

When investigating welfare fraud and welfare recipients, we find fewer associations with Dominance or Egalitarianism. However, we did find strong relationships with tax fraud, whereby higher Dominance was associated with perceptions that welfare recipients are more likely to be guilty and higher Egalitarianism was associated with perceptions that welfare recipients were less likely to be guilty.

The criminal justice system is more likely to apply harsh criminal sanctions against members of subordinate social groups than members of dominant social groups across a range of differentiating characteristics (Gross and Mauro, 1989; Baldus, Woodworth and Pulaski, 1990; Sidanius et. al, 2006). When a-minority groups with few resources, networks, or power receive support-is primarily supported by members of the same groupfrom in-groups, then it is perhaps unsurprising that theseis groups receives less favourable treatment in the justice system. Other groups that have greater power, resources, and networks are also more likely to receive support from similar people or groups, who also have greater power, resources, and networks.

The professional field of tax is largely the domain of elites: accountants, lawyers and economists. Tax laws are complex, which facilitates exploitation by those sufficiently 
knowledgeable to minimise payment obligations. Those who are privileged are more likely to commit tax fraud: typically, the fraudster has the funds axable income has been received or tax payable has been collected-before the fraud occurs. $\frac{16}{}$ This raises the potential for the embedding of practices when they benefit the interests of dominant groups (Chua, 1986) and act to reinforce privileged positions.

The results also suggest the presence of intergroup conflict. The literature predicts hostility towards the minority group, which is visible in the harsher treatment that welfare recipients receive in the investigation, prosecution and sentencing phases of the justice system. The presence of such in-groups and out-groups contributes to inequity, to the extent that preferences of the powerful do not extend beyond their own in-group.

Reference to the sociological literature reveals the status of welfare recipients as marginalised people. Fineman explains an often-accepted narrative when she writes 'we venerate the autonomous, independent, and self-sufficient individual as our ideal. We assume that anyone can cultivate these characteristics, consistent with our belief in the inherent equality of all members of our society, and we stigmatize those who do not' (Fineman, 2006:135). Moreover, we respect entrepreneurs and business owners, and hold in high esteem those who create jobs and 'contribute' to society - making excuses for their crimes when they are exposed. ${ }^{17}$ This social construction of what is fraudulent activity facilitates and reinforces inand out-group preference and restricts meaningful social change.

We acknowledge the limitations of this study. While we targeted a representative sample of the New Zealand and Australian populations, we did not receive responses that entirely matched the populations based on census data. The main concern in this regard is the underrepresentation of ethnic minority groups that are among the lower socio-economic groups (e.g. Pasifika and Māori). We used the SDO scale as a framework to assess prejudice. This instrument has been widely tested and is highly reliable. However, we acknowledge that different results may arise with the use of a different instrument. In addition, we have only examined one explanatory variable, which is prejudice. There are multiple factors that affect views of crimes, of which prejudice is only one.

\section{CONCLUSION}

This study adds to the literature on in-groups and out-groups specific to tax and welfare fraud, as comparable crimes. The fundamental premise of social dominance theory is that societies minimise conflict by creating consensus on ideologies that promote the superiority of one group over others (Pratto et al, 1994). This is visible in the data and findings previously outlined. The results of our survey show that in-groups hold preferable views of their own in-groups. Thus, to the extent that groups with more power or status view their own

\footnotetext{
${ }^{16}$ For example, when collection occurs, but payment to the government does not.

${ }^{17}$ Analysis by the authors of sentencing decisions of serious white-collar crime in New Zealand shows that the 'good character' of the offenders was a factor in reducing the sentence in $56 \%$ of cases.
} 
group as superior, we are unlikely to see significant change to the current differences in treatment of tax and welfare fraudsters.

Walzer (1983), in his theory of justice, suggests that social goods (or bads) should not be distributed based on some arbitrary characteristic. In this case, the characteristic is whether the person is in receipt of a welfare benefit. If someone is situated in a group with greater or fewer resources or power, this should not result in a different treatment in the justice system. Nor should it allow for influence over the treatment of other groups. Individuals should receive equal treatment, unless treating them unequally produces a more equitable outcome. However, in the absence of direct, deliberate action to address the different treatments in the justice system, it is unlikely that meaningful change will occur.

This leads to the role of critical research. With reference to critical research, Chua (1986:621) observes that in order to highlight restrictive conditions, it is necessary to demonstrate that 'so-called objective and universal social laws are but products of particular forms of domination and ideology'. While Chua is discussing accounting, her statement is equally applicable to taxation. Chua continues to observe that in challenging the status quo 'social change may be initiated such that injustice and inequities may be corrected' (1986:621). Herein lies the role of critical tax researchers.

In the same way that accounting researchers have identified that accounting theories are 'normative and value-laden in that they usually mask a conservative ideological bias', tax theories and practice may be equally accused. There is considerable capacity for critical tax research to have greater involvement in highlighting the potential for privileged individuals to receive privileged treatment in the justice system when committing 'privileged crimes' (Tinker, Merino and Neimark, 1982:167).

While this study focuses on tax, considerations for the accounting profession may be drawn. As noted in the previous section, accountants are one of the key groups that comprise the broad tax discipline. The in-group of accountants, which operates within an overarching ethical framework, may have an ethical duty to challenge behaviours whereby minority groups are the subject of discrimination. As argued by Bruna and Bazin supporting the Other...is an ethical duty' (2017:4). A further consideration for accountants relates to the finding of strong in-group preference. This preference is relevant for a profession that retains elements of self-regulation, as this study suggests that accountants are likely to have a more favourable view of accountants than other out-groups. This preference may further extend to other activities frequently provided in-house by accounting professional bodies, such as professional development and education.

Where powerful groups believe in the superiority of other similar powerful groups, this reinforces the status quo. This article has used the example of the different treatment of tax and welfare fraud in the justice systems of New Zealand and Australia to highlight prejudice and privilege. Given the findings in this study, there are significant societal issues that tax scholars can, and arguably should, be challenging. This study highlights the potential for critical tax research to challenge the privileged position that tax commands in society and to provide robust evidence-based challenges to the status quo. While tax avoidance by multinational enterprises has received greater focus in recent years, many of the discriminatory 
practices that exist at an operational level remain unchallenged. In New Zealand, universities have 'a role as critic and conscience of society' 18 and tax researchers are not heeding this obligation to the extent that critical tax research as a discipline in Australasia does not tackle issues of social justice. We follow the example of Lehman, Annisette and Agyemang (2013) in relation to critical accounting research, and call for critical tax researchers to assist in giving voice to the marginalised.

\footnotetext{
${ }^{18}$ Education Act 1989, s 4(a)(v).
} 


\section{REFERENCES}

Australian Institute of Criminology. (1986), "How the Public Sees Crime: An Australian survey", Trends \& Issues in Crime and Criminal Justice, Vol 2, pp. 1-6.

Baldus, D.C., Woodworth, G., and Pulaski, C.A. (1990), Equal Justice and the Death Penalty: A legal and empirical analysis, Northeastern University Press, Boston, MA.

Blumberg, Grace. (1971), "Sexism in the Code: A comparative study of income taxation of working wives and mothers", Buffalo Law Review, Issue 1, pp. 49-98.

Boden, R., Killian, S., Mulligan, E., and Oats, L. (2010), "Editorial: Critical Perspectives on Taxation", Critical Perspectives on Accounting, Vol 21, pp. 541-544.

Boden, R., Childs, M., and Wild, W. (1995), "Pride and Prejudice: Women, tax and citizenship", Critical Perspectives on Accounting, Vol 6, pp. 125-148.

Bright, R.A. (1978), "Dole Bludgers or Tax Dodgers: Who is the deviant?" in P. Wilson and J. Braithwaite, eds., Two Faces of Deviance: Crimes of the powerless and powerful. St Lucia: University of Queensland Press.

Brown, Dorothy, A. (2007), "Race and Class Matters", Columbia Law Review, Vol 107, No 3, pp. 790-831.

Brown, R. (1995), Prejudice: Its social psychology, Blackwell, Oxford.

Bruna, M.G., and Bazin, Y. (2017), “Answering Levinas' Call in Organization Studies”, European Management Review, DOI: 10.1111/emre.12137.

Cain, Patricia. (1991), "Same-Sex Couples and the Federal Tax Laws", Law \& Sexuality: A review of lesbian and gay legal issues", Vol 1, pp. 97-132.

Chua, Wai Fong. (1986), "Radical Developments in Accounting Thought", The Accounting Review, Vol 61, No 4, pp. 601-632.

Cook, D. (1989), Rich Law, Poor Law: Differential response to tax and supplementary benefit fraud, Open University Press, Milton Keynes.

Cook, D. (2006), Criminal and Social Justice, Sage Publications, London.

Cooper, D.J., Dacin, T., and Palmer, D. (2013), "Editorial: Fraud in accounting, organizations and society: Extending the boundaries of research", Accounting, Organizations and Society, Vol 38, p. 440-457.

Cowell, Frank, A. (1985), “Tax Evasion with Labour Income”, Journal of Public Economics, Vol 26, pp. 19-34.

Croall, H. (2001), Understanding White Collar Crime, Open University Press, Buckingham.

Croall, H. (2011), Crime and Society in Britain, $2^{\text {nd }}$ Edition, Pearson Education, Harlow, Essex.

Cullen, F.T., Link, B.G., and Polanzi, C.W. (1982), "The Seriousness of Crime Revisited", Criminology, Vol 20, No 1, pp. 83-102.

Darley, J.M., and Gross, P.H. (2000), “A Hypothesis-Confirming Bias in Labeling Effects", in C. Stangor (ed.), Stereotypes and Prejudice: Essential Readings, Taylor and Francis, Philadelphia.

Dillard, Jesse, F. (1991), “Accounting as a Critical Social Science”, Accounting, Auditing \& Accountability Journal, Vol 4, No 1, pp. 8-28.

Duckitt, J. (1992), The Social Psychology of Prejudice, Praeger, New York.

Duckitt, J. (2001), "A Dual-Process Cognitive-Motivational Theory of Ideology and Prejudice”, Advances in Experimental Social Psychology, Vol 33, pp.41-113.

Duckitt, J., Wagner, C., De Plessis, I., and Birum, I. (2002), "The Psychological Bases of Ideology and Prejudice: Testing a dual-process model", Journal of Personality and Social Psychology, Vol 83, No 1, pp. 75-93. 
Duckitt, J. and Sibley, C. (2010), "Right-Wing Authoritarianism and Social Dominance Orientation Differentially Moderate Intergroup Effects on Prejudice", European Journal of Personality, Vol 24, pp. 583-601.

Evans, M. and Kelley, J. (2001), "Are Tax Cheating and Welfare Fraud Wrong? Public opinion in 29 nations", Australian Social Monitor, Vol 3, No 4, pp. 93-102.

Falkinger, Josef. (1988), "Tax Evasion and Equity: A theoretical analysis", Public Finance, Vol 43, No 3, pp. 388-395.

Farrar, J. (2011), “Tax Fairness in Canadian Government Budgets: How fair is 'fair'?", Critical Perspectives on Accounting, Vol 22, pp. 365-375.

Fineman, M.A. (2006), Dependency and Social Debt, in D Grusky and R Kanbur (eds) Poverty and Inequality. Stanford: Stanford University Press.

Fishbein, M., and Ajzen, I. (1975), Belief, Attitude, Intention, and Behavior: An introduction to theory and research, Addison-Wesley Publishing Company, Reading, MA.

Forest, Adam, and Sheffrin, Steven. (2002), "Complexity and Compliance: an empirical investigation", National Tax Journal, Vol 55, No 1, pp. 75-90.

Gracia, Louise, and Oats, Lynne. (2012), "Boundary Work and Tax Regulation: A Bourdieusian view", Accounting, Organizations and Society, Vol 37, pp. 304-321.

Gross, S.R., and Mauro, R. (1989), Death and Discrimination: Racial disparities in capital sentencing, Northeastern University Press, Boston, MA.

Grown, Caren, and Valodia, Imraan. (2010), Taxation and Gender Equity: A comparative analysis of direct and indirect taxes in developing and developed countries, Routledge, London.

Gupta, R. (2006), "Perceptions of Tax Evasion as a Crime: Evidence from New Zealand", New Zealand Journal of Taxation Law and Policy, Vol 12, pp. 199-219.

Gustafson, K. (2009), "The Criminalization of Poverty", Journal of Criminal Law \& Criminology, Vol 99, No 3, pp. 643-716.

Hagan, J., Nagel, I., and Albonetti, C. (1980), "The Differential Sentencing of White-Collar Offenders in Ten Federal District Courts", American Sociological Association, Vol 45, No 2, pp. 802-820.

Hamilton, D.L., and Gifford, R.K. (2000), "Illusory Correlation in Interpersonal Perception: A cognitive basis of stereotypic judgments", in C. Stangor (ed.), Stereotypes and Prejudice: Essential Readings, Taylor and Francis, Philadelphia.

Ho, A., Sidanius, J., Pratto, F., Levin, S., Thomsen, L., Kteily, N. and Sheehy-Skeffington, J. (2012), "Social Dominance Orientation: Revisiting the structure and function of a variable predicting social and political attitudes", Personality and Social Psychology Bulletin, Vol 38, No 5, pp. 583-606.

Hudson, B. (1993), Penal Policy and Social Justice, MacMillan Press, Basingstoke.

Infanti, Anthony, C. (2008), “Tax Equity”, Buffalo Law Review, Vol 55, pp. 1191-1260.

Inland Revenue. (2016), Annual Report 2015/16, Inland Revenue, Wellington.

Karlinsky, S., Burton, H., and Blanthorne, C. (2004), "Perceptions of Tax Evasion as a Crime", eJournal of Tax Research, Vol 2, No 2, pp. 226-240.

Knauer, Nancy, J. (1998), "Heteronormativity and Federal Tax Policy", West Virginia Law Review, Issue 1, pp. 129-234.

Knauer, Nancy, J. (2014), “Critical Tax Policy: A pathway to reform?", Northwestern Journal of Law \& Social Policy, Vol 9, No 2, pp. 206-263.

Lehman, Cheryl, R., Annisette, Marcia, and Agyemang, Gloria. (2013), "Immigration and Neo-Liberalism: Three stories and counter accounts", APIRA 2013, Ref K184. Retrieved from: http://www.apira2013.org/proceedings/pdfs/K184.pdf, 19 February 2017.

Lehman, Cheryl, R., and Okcabol, Fahrettin. (2005), "Accounting for Crime", Critical Perspectives on Accounting, Vol 16, pp. 613-639. 
Lindley, J., Jorna, P., and Smith, R. (2010), Fraud Against the Commonwealth 2009-2010 Annual Report to Government, Australian Institute of Criminology, Canberra.

Livingston, Michael, A. (2002), "Women, Poverty and the Tax Code: A tale of theory and practice", Journal of Gender, Race and Justice, Issue 2, pp. 327-338.

Locke, V. and Johnston, L. (2001), "Stereotyping and Prejudice: A social cognitive approach", in Augoustinos, M. and Reynolds, K.J. (eds.), Understanding Prejudice, Racism, and Social Conflict, Sage Publications, London.

Marriott, L. (2010), The Politics of Retirement Savings Taxation: A Trans-Tasman Comparison, $\mathrm{CCH}$, Sydney.

Marriott, L. (2013), "Justice and the Justice System: A comparison of tax evasion and welfare fraud in Australasia", Griffith Law Review, Vol 22, No 2, pp. 403-429.

Marriott, L. (2014), "Unpaid Tax and Overpaid Welfare: A comparison of debt recovery approaches in New Zealand", New Zealand Journal of Taxation, Law and Policy, Vol 20, No 1, pp.46-70.

Marston, G., and Walsh, T. (2008), "A Case of Misrepresentation: Social security fraud and the criminal justice system in Australia", Griffith Law Review, Vol 17, No 1, pp. 285-300.

McIntosh, R.K., and Veal, J.A. (2001), "Tax Evasion and New Zealanders' Attitudes towards It", New Zealand Journal of Taxation Law and Policy, Vol 7, pp. 80-110.

McLean, D. (2003), The Prickly Pair: Making nationalism in Australia and New Zealand, University of Otago Press, Dunedin.

Ministry of Social Development. (2016), Annual Report 2015/16, Ministry of Social Development, Wellington.

Mitchell, Austin, Sikka, Prem, and Willmott, Hugh. (2001), "Policing Knowledge by Invoking the Law: Critical accounting and the politics of dissemination", Critical Perspectives on Accounting, Vol 12, pp.527-555.

Morales, Jérémy, and Sponem, Samuel. (2017), "You too can have a critical perspective! 25 years of Critical Perspectives on Accounting", Critical Perspectives on Accounting, Vol 43, pp. 149-166.

Moran, Beverly, I., and Whitford, William. (1996), "A Black Critique of the Internal Revenue Code", Wisconsin Law Review, Issue 4, pp. 751-820.

Mumford, Ann. (2009), Tax Policy, Women and the Law: UK and Comparative Perspectives, Cambridge University Press, Cambridge.

Nelken, D. (1997), "White-Collar Crime", in Maguire, M. Morgan, R. and Reiner, R. (eds.), The Oxford Handbook of Criminology, $2^{\text {nd }}$ Edition, Oxford University Press, Oxford.

Orviska, M and Hudson, J. (2002), "Tax Evasion, Civic Duty and the Law Abiding Citizen", European Journal of Political Economy, Vol 19, pp. 82-103.

Parker, Lee, D. (2011), "Twenty-One Years of Social and Environmental Accountability Research: A coming of age", Accounting Forum, Vol 35, pp. 1-10.

Piketty, Thomas. (2014), Capital in the Twenty-First Century, Harvard University Press, Boston.

Pratto, F., Sidanius, J., and Levin, S. (2006), "Social Dominance Theory and the Dynamics of Intergroup Relations: Taking stock and looking forward", European Review of Social Psychology, Vol 17, No 1, pp. 271-320.

Pratto, F., Sidanius, J., Stallworth, L. and Malle, B. (1994), "Social Dominance Orientation: A personality variable predicting social and political attitudes", Journal of Personality and Social Psychology, Vol 67, No 4, pp. 741-763.

Prenzler, T. (2010), "Detecting and Preventing Welfare Fraud", Trends \& Issues in Crime and Criminal Justice, Vol 418, pp. 1-6.

Reiman, J., and Leighton, R. (2013), The Rich get Richer and the Poor get Prison: Ideology, class, and criminal justice, $10^{\text {th }}$ Edition, Pearson, Boston. 
Sibley, C., Robertson, A. and Kirkwood, S. (2005), "Pakeha Attitudes toward the Symbolic and Resource-specific Aspects of Bicultural Policy in New Zealand: The legitimizing role of collective guilt for historical injustices", New Zealand Journal of Psychology, Vol 34, No 3, pp. 171-180.

Sidanius, J., Mitchell, M., Haley, H., and Navarette, C. (2006), "Support for Harsh Criminal Sanctions and Criminal Justice Beliefs: A social dominance perspective", Social Justice Research, Vol 19, No 4, pp. 433-449.

Sidanius, J. and Pratto, F. (1999), Social Dominance: An intergroup theory of social hierarchy and oppression, Cambridge University Press, Cambridge.

Sidanius, J., Pratto, F., van Laar, C., and Levin S. (2004), "Social Dominance Theory: Its agenda and method", Political Psychology, Vol 25, No 6, pp. 845-880.

Smith, G., Button, M., Johnston, L., and Frimpong, K. (2011), Studying Fraud as White Collar Crime, Palgrave MacMillan, Basingstoke.

Spicer, Michael, W., and Becker, Lee, A. (1980), "Fiscal Inequity and Tax Evasion: An Experimental Approach", National Tax Journal, Vol 33, No 2, 171-176.

Spicer, Michael, W., and Lundstedt, S.G. (1976) "Understanding Tax Evasion", Public Finance, Vol 31, No 2, pp. 295-305.

Sutherland, E.H. (1940), "White Collar Criminality", American Sociological Review, Vol 5, pp. 1-12.

Sutherland, E.H. (1949), White Collar Crime, Holt, Reinhart and Winston, New York.

Terry, D.J., Hogg, M.A., and Blackwood, L. (2001), "Prejudiced Attitudes, Group Norms, and Discriminatory Behaviour", in Augoustinos, M. and Reynolds, K.J. (eds.), Understanding Prejudice, Racism, and Social Conflict, Sage Publications, London.

Tinker, Anthony, M., Merino, Barbara, D., and Neimark, Marilyn, Dale. (1982), "The Normative Origins of Positive Theories: Ideology and accounting thought", Accounting, Organizations and Society, Vol 7, No 2, pp. 167-200.

Tuck, Penelope. (2010), "The Emergence of the Tax Official into a T-Shaped Knowledge Expert", Critical Perspectives on Accounting, Vol 21, No 7, pp. 584-596.

Wacquant, L. (2009), Punishing the Poor: The neoliberal government of social insecurity, Duke University Press, Durham.

Wallschutzky, Ian, G. (1988), The Effects of Tax Reform on Tax Evasion, Australian Tax Research Foundation, Sydney.

Walzer, M. (1983), Spheres of Justice: A defense of pluralism and equality, Basic Books, New York.

Weisburd, D., Wheeler, S., Waring, E., and Bode, N. (1991), Crimes of the Middle Classes: White-collar offenders in the federal courts, Yale University Press, New Haven. 


\section{Appendix I: Social Dominance Orientation Questions}

\begin{tabular}{|c|c|c|}
\hline & Question & Category \\
\hline 1 & All groups should be given an equal chance in life & Egalitarianism \\
\hline 2 & Some groups of people are just more worthy than others & Dominance \\
\hline 3 & Group equality should be our ideal & Egalitarianism \\
\hline 4 & $\begin{array}{l}\text { In getting what your group wants, it is sometimes necessary to } \\
\text { use force against other groups }\end{array}$ & Dominance \\
\hline 5 & $\begin{array}{l}\text { We should do what we can to equalise conditions for different } \\
\text { groups }\end{array}$ & Egalitarianism \\
\hline 6 & $\begin{array}{l}\text { It's OK if some groups have more of a chance in life than } \\
\text { others }\end{array}$ & Dominance \\
\hline 7 & We should increase social equality & Egalitarianism \\
\hline 8 & $\begin{array}{l}\text { To get ahead in life, it is sometimes necessary to step on other } \\
\text { groups }\end{array}$ & Dominance \\
\hline 9 & $\begin{array}{l}\text { We would have fewer problems if we treated groups more } \\
\text { equally }\end{array}$ & Egalitarianism \\
\hline 10 & $\begin{array}{l}\text { If certain groups of people stayed in their place, we would } \\
\text { have fewer problems }\end{array}$ & Dominance \\
\hline 11 & We should strive to make incomes more equal & Egalitarianism \\
\hline 12 & $\begin{array}{l}\text { It's probably a good thing that certain groups are at the top } \\
\text { and other groups are at the bottom }\end{array}$ & Dominance \\
\hline 13 & No one group should dominate in society & Egalitarianism \\
\hline 14 & Inferior groups should stay in their place & Dominance \\
\hline 15 & Sometimes other groups must be kept in their place & Dominance \\
\hline 16 & It would be good if all groups could be equal & Egalitarianism \\
\hline
\end{tabular}


SOCIAL INEQUITY, TAXES AND WELFARE IN AUSTRALASIA

Response to Editors' Comments (Reference AAAJ-02-2016-2432.R3)

\begin{tabular}{|c|c|}
\hline Editors' Comments & Action taken \\
\hline $\begin{array}{l}\text { The abstract is a little too long for AAAJ, which } \\
\text { has a } 250 \text { word limit. We suggest trimming to } \\
\text { just the key points (e.g. removing the second } \\
\text { sentence in the 'purpose' section, and } \\
\text { removing the clause after 'in-group' in the final } \\
\text { sentence of 'findings') }\end{array}$ & $\begin{array}{l}\text { Amended as suggested, together with another } \\
\text { couple of changes to reduce the word count. } \\
\text { The abstract is now } 244 \text { words (including the } \\
\text { headings). }\end{array}$ \\
\hline $\begin{array}{l}\text { Also, we requested in the previous review that } \\
\text { the 'value' section of the abstract refer more } \\
\text { directly to the contribution to accounting. Since } \\
\text { the contribution to accounting research is a key } \\
\text { part of AAAJ's remit, we would again suggest } \\
\text { rephrasing the value section to stress the } \\
\text { contribution to prior accounting research }\end{array}$ & $\begin{array}{l}\text { I have amended the 'value' section as } \\
\text { suggested. }\end{array}$ \\
\hline $\begin{array}{l}\text { While the paper's discussion of its main aims } \\
\text { has improved, there still seems to be some } \\
\text { confusing passages. In particular, p. } 2 \text {, lines } 32 \\
\text { to } 36 \text { appear to mention three aims, but then } \\
\text { line } 8, \text { p. } 3 \text { begins with 'The second major aim } \\
\text { of the study...'. Consistent with our } \\
\text { understanding of your abstract, could the } \\
\text { several aims on p. } 2 \text { be incorporated under one } \\
\text { clearly signalled 'first' aim? }\end{array}$ & $\begin{array}{l}\text { Apologies for the confusion. I have rewritten } \\
\text { this paragraph on page } 2 \text {. }\end{array}$ \\
\hline $\begin{array}{l}\text { There are still opportunities to streamline the } \\
\text { writing by replacing passive with active voice } \\
\text { (e.g. social scientist use, vs. used by social } \\
\text { scientists (p. 8); issues Infanti and Knauer raise; } \\
\text { vs. issued raised by Infanti and Knauer (p. 12); } \\
\text { Boden et al. ( } 2010 \text { ) further develop this idea, } \\
\text { vs. this idea is further developed by Boden et al } \\
\text { (p. 13); positivism typically dominates tax } \\
\text { research, vs. the field of tax research is typically } \\
\text { the domain of positivism, vs (p. 13) etc.). }\end{array}$ & $\begin{array}{l}\text { Apologies (again). I have amended all those } \\
\text { suggested, together with a number of other } \\
\text { instances throughout the article. }\end{array}$ \\
\hline
\end{tabular}

